\title{
The Biochemistry and Regulation of S100A10: A Multifunctional Plasminogen Receptor Involved in Oncogenesis
}

\author{
Patricia A. Madureira, ${ }^{1,2}$ Paul A. O'Connell, ${ }^{2}$ Alexi P. Surette, ${ }^{2}$ \\ Victoria A. Miller, ${ }^{2}$ and David M. Waisman ${ }^{2,3}$ \\ ${ }^{1}$ Centro de Biomedicina Molecular e Estrutural, University of Algarve, Campus of Gambelas, FCT Bld. 8, 8005-139 Faro, Portugal \\ ${ }^{2}$ Department of Biochemistry \& Molecular Biology, Dalhousie University, P.O. Box 1500, Halifax, NS, Canada B3H 4R2 \\ ${ }^{3}$ Department of Pathology, Dalhousie University, P.O. Box 1500, Halifax, NS, Canada B3H 4R2
}

Correspondence should be addressed to David M. Waisman, david.waisman@dal.ca

Received 9 April 2012; Accepted 1 June 2012

Academic Editor: Lindsey A. Miles

Copyright ( 2012 Patricia A. Madureira et al. This is an open access article distributed under the Creative Commons Attribution License, which permits unrestricted use, distribution, and reproduction in any medium, provided the original work is properly cited.

\begin{abstract}
The plasminogen receptors mediate the production and localization to the cell surface of the broad spectrum proteinase, plasmin. S100A10 is a key regulator of cellular plasmin production and may account for as much as $50 \%$ of cellular plasmin generation. In parallel to plasminogen, the plasminogen-binding site on S100A10 is highly conserved from mammals to fish. S100A10 is constitutively expressed in many cells and is also induced by many diverse factors and physiological stimuli including dexamethasone, epidermal growth factor, transforming growth factor- $\alpha$, interferon- $\gamma$, nerve growth factor, keratinocyte growth factor, retinoic acid, and thrombin. Therefore, S100A10 is utilized by cells to regulate plasmin proteolytic activity in response to a wide diversity of physiological stimuli. The expression of the oncogenes, PML-RAR $\alpha$ and KRas, also stimulates the levels of S100A10, suggesting a role for S100A10 in pathophysiological processes such as in the oncogenic-mediated increases in plasmin production. The S100A10-null mouse model system has established the critical role that S100A10 plays as a regulator of fibrinolysis and oncogenesis. S100A10 plays two major roles in oncogenesis, first as a regulator of cancer cell invasion and metastasis and secondly as a regulator of the recruitment of tumor-associated cells, such as macrophages, to the tumor site.
\end{abstract}

\section{Introduction}

Several fundamental studies have shown that cellular receptors for plasminogen play a major role in the regulation of important physiological processes such as fibrinolysis and in the development of disease, such as cancer [1-4]. The binding of the blood protein and zymogen, plasminogen, to specific cell surface receptors, called plasminogen receptors, significantly increases the rate of its proteolytic conversion to plasmin, due to the colocalization of plasminogen with its activators, tissue plasminogen activator (tPA) and the urokinase-type plasminogen activator (uPA) $[5,6]$. Although tPA shares the same cellular binding sites as plasminogen [79], uPA is localized to the cell surface by its binding to its cell surface receptor, the urokinase-type plasminogen receptor
(uPAR) [10]. Many intracellular and extracellular functions have been proposed for S100A10, of which probably the most striking in terms of physiological significance and implications for disease is the extracellular function of this protein as a plasminogen receptor (reviewed in [1114]). S100A10 binds to tPA and plasminogen and also colocalizes with the uPA/uPAR complex, which stimulates the conversion of plasminogen to the broad specificity protease, plasmin. Plasmin also binds to S100A10 which protects the newly generated plasmin from inactivation by its inhibitor, $\alpha_{2}$-antiplasmin, and also serves to focus the proteolytic activity of plasmin to the cell surface [15]. S100A10 also stimulates plasmin autoproteolysis, resulting in the destruction of plasmin and the generation of bioactive plasmin fragments, the angiostatins (reviewed in [16]). A 
main characteristic of the plasminogen receptors is the presence of a carboxyl-terminal lysine residue that binds to the kringle domains of plasminogen $[9,13,17,18]$. S100A10 possesses two carboxyl-terminal lysine residues that have been shown to bind both TPA and plasminogen and to play a critical role in the conversion of plasminogen to plasmin by the plasminogen activators $[19,20]$. Several plasminogen receptors have been reported that do not contain a carboxylterminal lysine residue, but it is unclear as to what extent these proteins contribute to cellular plasmin generation.

In this paper we will review, in detail, the structure and function of S100A10. Although both intracellular [21, 22] and extracellular roles [12] have been identified for S100A10, the main focus of this paper will be on the extracellular role of S100A10 as a plasminogen receptor. We will develop two themes, highlighted by studies of the S100A10-null mouse. The first is that S100A10 is a highly inducible plasminogen receptor. S100A10 is not only regulated by physiologically important signaling molecules such as thrombin [23], epidermal growth factor [24, 25], transforming growth factor- $\alpha[26]$, and interferon- $\gamma[27$, 28], but also by pathophysiological events such as the expression of oncogenes that occurs during the process of tumor development and progression (oncogenesis) [29, 30]. Second, we will summarize our observations that document that S100A10 is responsible for a significant amount of total cellular plasmin generation and develop the second theme that S100A10 plays a key role in physiological processes, such as fibrinolysis and inflammation. Collectively, we will showcase the concept that in response to both physiological and pathophysiological cues, cells utilize S100A10 to regulate their levels of plasmin proteolytic activity. Our working model of cellular plasmin regulation by S100A10 is presented in Figure 1.

\section{Historical Perspective}

S100A10 was first identified in 1984 during the purification of a $34 \mathrm{kDa}$ protein substrate of Rous sarcoma virustransforming protein tyrosine kinase $\left(\mathrm{pp} 60^{\mathrm{v}-\mathrm{src}}\right)$ from chicken embryo fibroblasts [31]. These investigators observed the presence of a small, $6 \mathrm{kDa}$ protein that was present at the dye front of Coomassie blue-stained SDSpolyacrylamide gels. Using preparations from porcine or bovine epithelial cells, this protein was estimated to have a molecular mass of $11 \mathrm{kDa}$ and found to share homology with the glia-specific protein, S-100, and to share about 50\% amino acid homology with $S 100 \alpha[32,33]$.

Since its discovery, many proposed intracellular functions have been suggested for S100A10. In the late 1980s and early 1990s the binding of S100A10 to the protein annexin A2 was shown to diminish the phosphorylation of annexin $\mathrm{A} 2$, and thereby regulate the association of annexin A2 with phospholipid membranes [32, 34, 35]. S100A10 was also shown to stimulate annexin A2 translocation to the cortical cytoskeleton [36] and stimulate the F-actin bundling activity of annexin A2 during exocytosis [37-39]. Again, in complex with annexin A2, S100A10 was reported to enhance the annexin A2 stimulation of glial fibrillary acidic protein (GFAP) polymerization [40] and to play a role in cytomegalovirus infection $[41,42]$. S100A10 was also shown to have a role in inhibiting inflammation, by targeting phospholipase A2 [43]. The interaction of S100A10 with the $\mathrm{Bcl}$-2-associated death promoter (BAD) was shown to inhibit the proapoptotic activity of the protein [44]. The interaction of S100A10 with PCTAIRE-1 was reported to stimulate its protein kinase activity $[45,46]$. It was also noted that S1000A10 was a transglutaminase substrate although the functional significance of this modification is unclear [47].

The early part of 2000 saw a flurry of publication on S100A10. In complex with bluetongue virus protein, NS3, S100A10 was shown to mediate virus release [48]. S100A10 in association with HBV Pol was also reported to inhibit DNA polymerase activity [49]. The binding of S100A10 to AHNAK was also reported [50]. During this time, a role for S100A10 in the regulation of plasma membrane ion channels was reported. S100A10 was shown to complex with the twopore domain acid-sensitive potassium channel (TASK-1) at the plasma membrane [51], and interact with the transient receptor potential cation channel subfamily $\mathrm{V}$ member 5/6 (TRPV5/TRPV6) [52], the acid-sensing ion channel 1 (ASIC-1) [53], and with the voltage-gated sodium channel NaV1.8 [54, 55]. The year 2006 saw reports of the interaction of the S100A10 protein with the serotonin receptor, 5-HT1B [56]. Perhaps the most exciting development in the S100A10 field came with the development of the S100A10 gene knockout (S100A10-null) mouse. Using a mouse knockout that entailed a specific S100A10 deletion in nociceptive sensory neurons, it was reported that S100A10 played a role in nociception, resulting from decreased sodium current [57]. This study confirmed the role of S100A10 in the regulation of the expression of $\mathrm{Na}(\mathrm{V}) 1.8$. This study also reported that knockout of S100A10 did not affect the protein levels of its annexin A2 binding partner. A general S100A10 mouse knockout model also indicated the physiological relevance of the S100A10-5-HT1B receptor interaction. They found that these S100A10-null mice are viable but exhibited a depression-like phenotype with reduced responses to 5HT1B agonists, suggesting that S100A10 is not required for normal mouse development, but that lack of S100A10 causes a depressive disorder due to its regulation of the 5-HT1B channels [56].

Since S100A10 can only be purified from tissues as a complex with annexin A2, our initial studies compared the structure and function of annexin A2 monomer and the annexin A2/S100A10 complex isolated from bovine lung. We called the annexin A2/S100A10 complex, the annexin A2 heterotetramer (abbreviated as AIIt). We reported, in 1998, that annexin A2/S100A10 complex purified from bovine lung, regulated plasmin activity by stimulating plasmin autoproteolysis $[58,59]$. We also observed that other purified annexins, including annexin A2, did not appreciably stimulate plasmin autoproteolysis. Later studies would reveal that the plasmin fragments produced by AIIt-dependent plasmin autoproteolysis were biologically active antiangiogenic molecules [60, 61]. An extracellular function for S100A10 as a plasminogen receptor was initially suggested in the late $90^{\prime} \mathrm{s}$ 


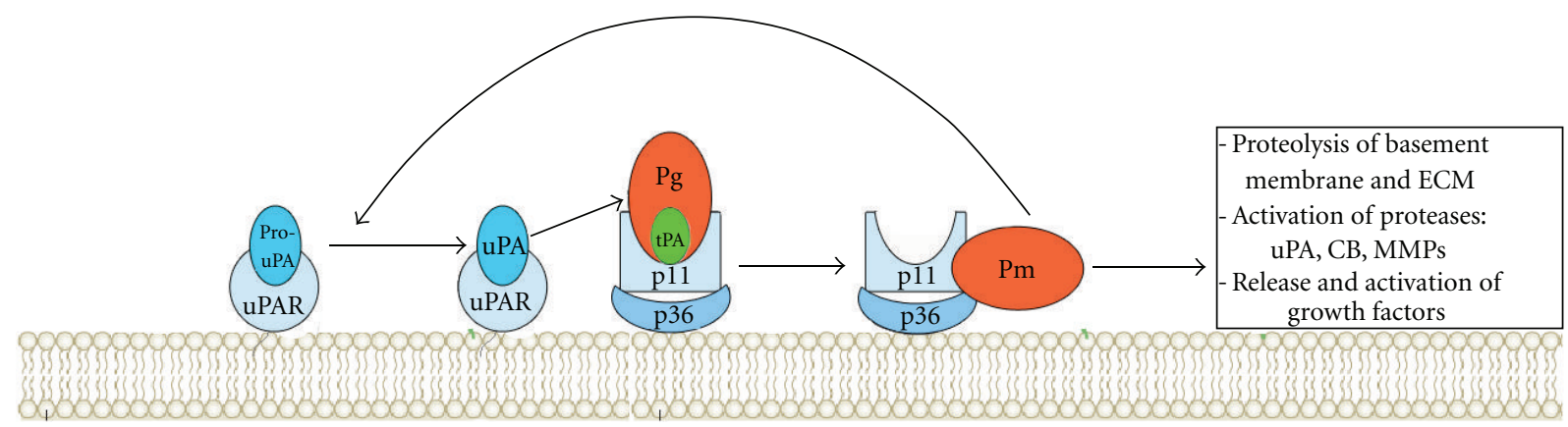

Plasma membrane

FIGURE 1: Regulation of cellular plasmin generation by S100A10. Normal cells and cancer cells utilize the plasminogen receptor, S100A10 (p11), for cell surface plasmin generation. The predominant form of S100A10 at the cell surface is as the heterotetramer, AIIt which consists of two copies of the annexin A2 (p36) and a S100A10 homodimer. The model shows one-half of this heterotetrameric complex. Annexin A2 acts as a regulatory subunit which utilizes its phospholipid-binding sites to anchor S100A10 to the cell surface. S100A10 binds tPA and plasminogen $(\mathrm{Pg})$ at its carboxyl-terminal lysine residue. It is unclear if one molecule of AIIt can bind both tPA and plasminogen at each of the binding sites on the antiparallel S100A10 monomers or if each molecule of AIIt can only bind two molecules of tPA or two molecules of plasminogen at the S100A10 monomers. The localization of tPA and plasminogen in close proximity promotes the rapid conversion of plasminogen to plasmin (Pm) by tPA. Plasmin binds to both annexin A2 and S100A10 at sites distinct from the plasminogen-binding site. The protease, urokinase-type plasminogen activator ( $\mathrm{uPA}$ ), is secreted from cells in its inactive, zymogen form called pro-uPA. Pro-uPA is converted to uPA by several proteases including plasmin. The uPA/uPAR complex colocalizes with the AIIt where uPA cleaves the S100A10bound plasminogen, generating plasmin. Plasmin cleaves and activates promatrix metalloproteases (MMPs), procathepsin B (pro-CB), and pro-uPA. Plasmin, MMPs, and cathepsin B degrade many extracellular matrix (ECM) proteins and both release and activate growth factors from the ECM via proteolysis. Increased cell surface concentration of uPA or pro-uPA (by binding to its receptor, uPAR) and plasmin or plasminogen (by binding to S100A10) accelerates their reciprocal activation and focuses plasmin proteolytic activity to the cell surface.

by our laboratory. We observed that S100A10 was present on the surface of cells, predominantly in a complex with annexin A2, and that this complex dramatically stimulated tPA-dependent plasmin formation [15]. Using an in vitro assay with purified components, we showed that the the annexin A2/S100A10 complex stimulated the rate of activation of [Glu] plasminogen about 341-fold compared with an approximate 6-fold stimulation by monomeric annexin A2. These studies suggested that S100A10 and not annexin A2 was an important regulator of plasmin generation and plasmin activity. The cloning and purification of full-length human recombinant annexin A2 and S100A10 in 1997 [62] allowed the detailed characterization of the interaction of tPA and plasminogen with S100A10 complexed with annexin $\mathrm{A} 2$ as well as, for the first time, with the free S100A10 homodimer. We reported that the human recombinant annexin A2/S100A10 complex stimulated tPA-dependent plasminogen activation by about 77 -fold compared with about 2- and 46-fold for human recombinant annexin A2 monomer and homodimeric S100A10, respectively [19]. We also showed that the loss of the carboxyl-terminal lysine residues of homodimeric S100A10 or S100A10 complexed to annexin A2 blocked tPA-dependent plasminogen activation $[19,20]$. Finally, we showed that the addition of a peptide to the S100A10 binding site of annexin A2 (the aminoterminal 15 amino acids), to the recombinant S100A10 homodimer, increased the rate of tPA-dependent plasminogen activation by two-fold compared with the stimulation by homodimeric S100A10 alone [19]. The activity of this truncated recombinant complex, formed by the binding of this peptide to the recombinant S100A10 homodimer (annexin
A2 $(1-15) / S 100 A 10)$, was comparable to the activity of the intact annexin $\mathrm{A} 2_{(1-338)} / \mathrm{S} 100 \mathrm{~A} 10$ complex. This indicated that within the annexin A2/S100A10 complex, S100A10 was the subunit directly responsible for plasmin generation and that the interaction of annexin A2 with S100A10 functioned to stimulate the activity of S100A10. These studies were extended in 2003 when we used surface plasmon resonance to examine the interaction of tPA and plasminogen with homodimeric S100A10 and S100A10 complexed with annexin A2 [63]. We reported that homodimeric S100A10 bound tPA and plasminogen and that S100A10 complexed with annexin A2 bound plasminogen with higher affinity than homodimeric S100A10. Since we also observed that annexin A2 did not bind tPA or plasminogen, we concluded that the binding of annexin A2 to S100A10 increased the affinity of S100A10 for plasminogen.

In 2003-2004 we used antisense RNA or small interfering RNA (shRNA) to selectively deplete S100A10 from cells. These studies established that S100A10 contributed significantly to the total cellular plasmin generation and that S100A10-dependent plasmin generation was utilized by cancer cells to promote invasion and metastasis $[64,65]$. In 2010-2011 studies with the S100A10-null mouse contributed greatly to our understanding of the role of S100A10 as a plasminogen receptor. We found that mice deficient in S100A10 had increased fibrin deposition in various tissues including the lungs, liver, spleen, and kidney. These mice exhibited impaired fibrinolysis, illustrated by an inability to clear microclots formed by the snake venom, batroxobin. These mice also showed decreased angiogenesis, evidenced by a decreased infiltration of endothelial cell into Matrigel 
plugs [66]. We also demonstrated that cell surface S100A10 played an important role in the migration of macrophages to the site of inflammation [67]. Our lab group recently explored the role of S100A10 on the surface of macrophages and the ability of these cells to enhance tumor growth [68]. Mice deficient in S100A10 grew smaller tumors than their wild-type counterparts, but injection of macrophages that express S100A10 into the tumors of the S100A10-null mice resulted in an increase in tumor growth rate similar to that of wild-type mice. These studies established that S100A10 was essential and sufficient for macrophage migration to tumor sites, and that the S100A10-dependent migration of macrophages to the tumor site was a novel rate-limiting step in tumor progression.

Most recently, two studies have contributed greatly to our understanding of the regulation of S100A10. In 2011, Lin's group demonstrated that the transport of S100A10 to the extracellular surface requires annexin A2 and is mediated by the exosomal transport pathway [28]. During this time, it was also shown that the expression of the protein, DLC1, resulted in the binding of DLC1 to S100A10 which decreased the S100A10 levels because DLC1 displaced annexin A2 from S100A10 which resulted in the ubiquitin-dependent degradation of S100A10 [69]. This result established that a primary function of annexin A2 was to protect S100A10 from degradation, a property not shared by all S100A10-binding proteins.

\section{S100A10 Structure}

The S100 family of proteins are small acidic calcium-binding proteins of $9-13 \mathrm{kDa}$ that, excluding pseudo genes and fused S100 proteins, consist of about 20 genes (reviewed in [7072]). Sixteen S100 genes are tightly clustered in a region of the human chromosome 1q21 and are designated as S100A followed by Arabic numbers (S100A1-S100A16). Another four S100 genes outside the 1q21 locus carry a single-letter stem symbol (S100B, S100P, S100Z, and S100G). The S100 proteins belong to a large family of $\mathrm{Ca}^{2+}$-binding proteins called the EF hand superfamily that includes proteins such as calmodulin, parvalbumin, troponins, and CaBPs [73]. On the basis of the parvalbumin structure, Kretsinger identified the structure responsible for $\mathrm{Ca}^{2+}$ binding and coined the term for this $\mathrm{Ca}^{2+}$-binding structure as the EF hand motif [74].

The S100 proteins typically contain two EF hand motifs (two $\alpha$-helices linked by a $\mathrm{Ca}^{2+}$-binding loop): an S100specific EF hand at the N-terminus and a canonical EF hand at the C-terminus. In all of the S100 proteins except S100A10, the $\mathrm{EF}$ hands are responsible for $\mathrm{Ca}^{2+}$-binding. These EF hands are not equivalent as the carboxyl-terminal EF hand $\mathrm{Ca}^{2+}$-binding loop contains the classical 12-amino-acid $\mathrm{Ca}^{2+}$ binding motif that is common to all EF hand $\mathrm{Ca}^{2+}$-binding proteins such as parvalbumin and calmodulin. In this motif, $\mathrm{Ca}^{2+}$-binding occurs via acidic side chains that comprise the sequence DXDGDGTIXXXE. In contrast, the N-terminal EF hand motif is a 14-amino-acid $\mathrm{Ca}^{2+}$ binding loop which is characteristic of all S100 proteins and is referred to as the
S100 specific or pseudo EF domain. This motif binds $\mathrm{Ca}^{2+}$ via backbone carbonyl groups and only by one carboxylate side group of glutamic acid [75]. Some of the S100 proteins also bind zinc and copper cations at sites distinct from the EF hand motifs [76]. In addition to the EF domains, the S100 proteins also possess a carboxyl-terminal extension. Some S100 proteins have long and flexible carboxyl-terminal extensions and this region has been suggested to be required for a ligand interaction independent of the EF hand. In general, the carboxyl-terminal extension exhibits the highest sequence variation and has been suggested to be a major contributor to the specificity of S100 proteins [77].

Calmodulin was the first multifunctional EF hand containing $\mathrm{Ca}^{2+}$-binding protein that was shown to be highly conserved and present in all eukaryotes [78]. In contrast, the S100 protein family has been proposed to have originated during the Ordovician period, about 460 million years ago, with the evolution of vertebrates. S100 proteins most likely originated from a calmodulin-type precursor protein by gene duplication or exon recombination with subsequent loss of two of the four EF hands [73, 75, 79]. S100 proteins have been only isolated from vertebrates, and the analysis of the available genomes of nonvertebrate eukaryotes such as nematodes, insects, and protozoa has suggested the absence of S100-like sequences from these organisms [80]. This suggests that $\mathrm{S} 100$ proteins form a phylogenetically young group among the EF hand proteins. Despite their phylogenetic short history, the diversification in the S100 family is so extensive, that the $\mathrm{S} 100$ proteins actually form the largest subgroup among the EF hand proteins. The members of the S100 protein family are multifunctional signaling proteins that are involved in the regulation of diverse cellular processes such as transcription, secretion, contraction, motility, cell growth, differentiation, and cell cycle progression. Diseases associated with altered expression levels of S100 proteins include diseases of the heart, diseases of the central nervous system, inflammatory disorders, and cancer progression (reviewed in [77]). The diversity of binding partners for the $\mathrm{S} 100$ proteins is illustrated by the reports that $\mathrm{S} 100$ proteins are involved in at least 68 interactions with non-S100 targets (IntAct database of binary interactions (http://www.ebi.ac.uk/intact/). In fact, one S100 family member, S100A8, has been reported to interact with as many as 27 partners [81]. One of the possible explanations for the functional versatility of $\mathrm{S} 100$ proteins is the recent suggestion that most of the $\mathrm{S} 100$ proteins are intrinsic disordered proteins and as a result of structural plasticity, these proteins can interact with different targets and in some cases adopt different conformations, depending upon the specific ligand bound [82].

The majority of $\mathrm{S} 100$ proteins form symmetric noncovalent homodimers, a feature that is unique to the EF hand family. The dimer is formed by the interaction of helices I and IV of each monomer thus forming an antiparallel structure. Although infrequent, heterodimers have been shown to form between certain S100 proteins, such as that formed between S100A8 and S100A9 [83]. The only monomeric S100 family member is S100G (calbindin-D9k). Upon $\mathrm{Ca}^{2+}$ binding, all S100 proteins except S100A13 [84] undergo a 
conformational change that results in a large reorientation of helix III whereas helix IV and the N-terminal EF hand show only minor structural changes. Specifically, the $\mathrm{Ca}^{2+}$ binding event results in the N-terminus of helix III shifting by about 40 degrees relative to helix IV which results in helix III adopting a position that is nearly perpendicular to helix IV. As a consequence five hydrophobic residues on helix IV, as well as on two hydrophobic residues in helix I and three hydrophobic residues in the hinge region which was previously buried in the $\mathrm{Ca}^{2+}$-free state, are exposed and form the site utilized for ligand interactions (reviewed in [72]).

S100A10 is unique among S100 family members in that its EF hands cannot bind $\mathrm{Ca}^{2+}$. Each S100A10 monomer is composed of four $\alpha$-helical domains of variable length referred to as H-I (Q3-A19), H-II (K27-K36), H-III (A50L58), and H-IV (F68-H89) (Figure 2). Separating H-I and $\mathrm{H}$-II helical regions is a loop which along with contributions from $\mathrm{H}-\mathrm{I}$ and $\mathrm{H}-\mathrm{II}$ forms a $\mathrm{Ca}^{2+}$-binding loop (L1; A19-L30) and the H-I-L1-H-II domain forms the S100-specific, EF-1 domain. The H-III and H-IV domains are separated by a second loop (L2; D59-S70) and the H-III-L2-H-IV domain forms the canonical EF hand motif, EF-2. The EF-1 and EF-2 domains are connected by a flexible linker or hinge region (HR1: P39-N44). S100A10 has three deletions in L1 thus rendering this domain incapable of binding $\mathrm{Ca}^{2+}$. Two substitutions involving a glutamic and asparagine residue in EF-2 of S100A10 also render this domain incapable of binding $\mathrm{Ca}^{2+}$. Although the EF hands of S100A10 are unable to bind $\mathrm{Ca}^{2+}$, the conformation of S100A10 resembles the $\mathrm{Ca}^{2+}$ "on" state of other S100 proteins, therefore the mutations in S100A10 result in a constitutively active conformation [85]. Thus the interaction of S100A10 with its best characterized ligand, annexin $\mathrm{A} 2$, is $\mathrm{Ca}^{2+}$ independent [62].

$\mathrm{X}$-ray crystallographic analysis and site-directed mutagenesis studies have revealed that a hydrophobic cleft formed by the hinge HR1 and helix H-IV of one monomer and helix H-I of the other monomer of S100A10 form the binding site with the amino-terminal region of annexin A2 [85-88]. These points of interaction between annexin $\mathrm{A} 2$ and S100A10 are quite extensive. Four hydrophobic amino acids of the amino terminus of annexin A2 (V3, I6, L7, and L10) form seven points of contact with helix H-I of one monomer, two points of contact with the hinge region, and nine points of contact with helix H-IV of the other monomer, for a total of nineteen points of contact between annexin $\mathrm{A} 2$ and S100A10 (reviewed in [71]). In addition, T2 of S100A10 interacts with E9 and F13 of H-I (A. Rety, personal communication). Sitedirected mutagenesis experiments have identified important interactions between annexin A2 and Y85 and F86 of helix H-IV of one S100A10 monomer and E5 and E9 of helix HI of the other monomer [88]. The interaction of S100A10 with annexin A2 produces a heterotetrameric complex that is referred to as AIIt. This interaction affects the structure of both molecules. Annexin A2 aggregates chromaffin granules with a $\mathrm{K}_{\mathrm{d}}\left(\mathrm{Ca}^{2+}\right)$ in the millimolar range. Partial proteolysis results in the removal of the first 27 or 43 residues of the amino terminus and reduces the $\mathrm{K}_{\mathrm{d}}\left(\mathrm{Ca}^{2+}\right)$ for chromaffin granule aggregation about 10 - or 50 -fold, respectively. The binding of the S100A10 to the annexin A2 also reduces the $\mathrm{K}_{\mathrm{d}}\left(\mathrm{Ca}^{2+}\right)$ of chromaffin granule about aggregation to about $2 \mu \mathrm{M}$. This suggests that the amino-terminus exerts an inhibitory constraint on the interaction of annexin A2 with its biological targets whereas the binding of the S100A10 reverses this inhibitory restraint (reviewed in [39]).

As discussed, $\mathrm{S} 100$ proteins interact with a large variety of target molecules and S100A10 is certainly no exception (reviewed in $[12,21,22])$. S100A10 (in association with annexin A2 as the heterotetrameric complex, AIIt) participates in the recruitment and/or function of $\mathrm{Na}^{+}, \mathrm{K}^{+}, \mathrm{Ca}^{2+}$, and $\mathrm{Cl}^{-}$channels and serotonin receptors $([51,52,54,56$, 89]. Other proteins have been reported to bind S100A10, including phospholipase A2 [43], cathepsin B [90, 91], BAD [44], PCTAIRE1 [46], DLC1 [69], and AHNAK [50]. The site of interaction of S100A10 with the bluetongue virus protein, NS3 (M-L-S-G-L-I-Q-R-F-E-E-E) [48], TASK-1 (GF-R-N-V-Y-A-E-V-L-H-F) [51], AHNAK (G-K-V-T-F-P-KM-K-I-P-K-F-T-F-S-G-R-E-L) [92], and DLC1 (S-T-F-N-NV-V-E-Q-N-F-K) [69] has been reported. The binding site between S100A10 and annexin A2 (T-V-H-E-I-L-C-K-L-C) forms the general interaction motif (X-O-O-X-X-O-O-X$\mathrm{O}$ ) where $\mathrm{X}$ refers to hydrophobic residues and $\mathrm{O}$ is any other residue [93]. The binding region of AHNAK which binds to both annexin A2 and S100A10 within the AIIt complex, only partially possesses this motif. However, both NS3 and TASK-1 show similarities to this motif and both of these proteins appear to compete with annexin A2 for S100A10. Importantly, the amino-terminal region of annexin A1, (AMVSEFLKQAWFI) does not interact with S100A10 but possesses a similar motif.

The competition of ligands for the annexin A2 binding site on S100A10 has important consequences for the stability of S100A10. The detailed study of the interaction of S100A10 with DLC1 established that annexin A2 serves to protect S100A10 from ubiquitin-mediated degradation and ligands that displace annexin A2 from S100A10 will cause the rapid degradation of S100A10. It has been suggested that many of the binding partners of S100A10 may utilize the protein as a mechanism of cotransport to the plasma membrane; however if the binding of these ligands results in the disassociation of annexin A2 then rapid degradation of the S100A10-ligand complex would be expected. Therefore only ligands that bind to both subunits and/or do not dissociate annexin A2 from S100A10 would benefit from binding to S100A10. It was also interesting that overexpression of DLC1 which resulted in the depletion of S100A10 levels resulted in the inhibition of plasmin generation and invasion of aggressive lung cancer cells [69]. This study therefore confirmed the importance of S100A10 as a plasminogen receptor and regulator of cellular plasmin generation [29, 64-68]. This study also provided important structural information on the ligand binding motif between S100A10 and DLC1 and annexin A2. A comparison of the binding regions of annexin A2 (S-T-V-H-E-I-L-C-K-L-S) with DLC1 (S-T-F-N-N-V-VE-Q-N-F-K) suggests that a minimal binding motif may be $\mathrm{T}-\mathrm{X}-\mathrm{O}-\mathrm{O}-\mathrm{X}-\mathrm{X}-\mathrm{O}$ ) in which $\mathrm{L} 10$ of annexin A2 does not play an important role in binding to S100A10. Consistent with this suggestion is that the interaction of L10 forms only weak 


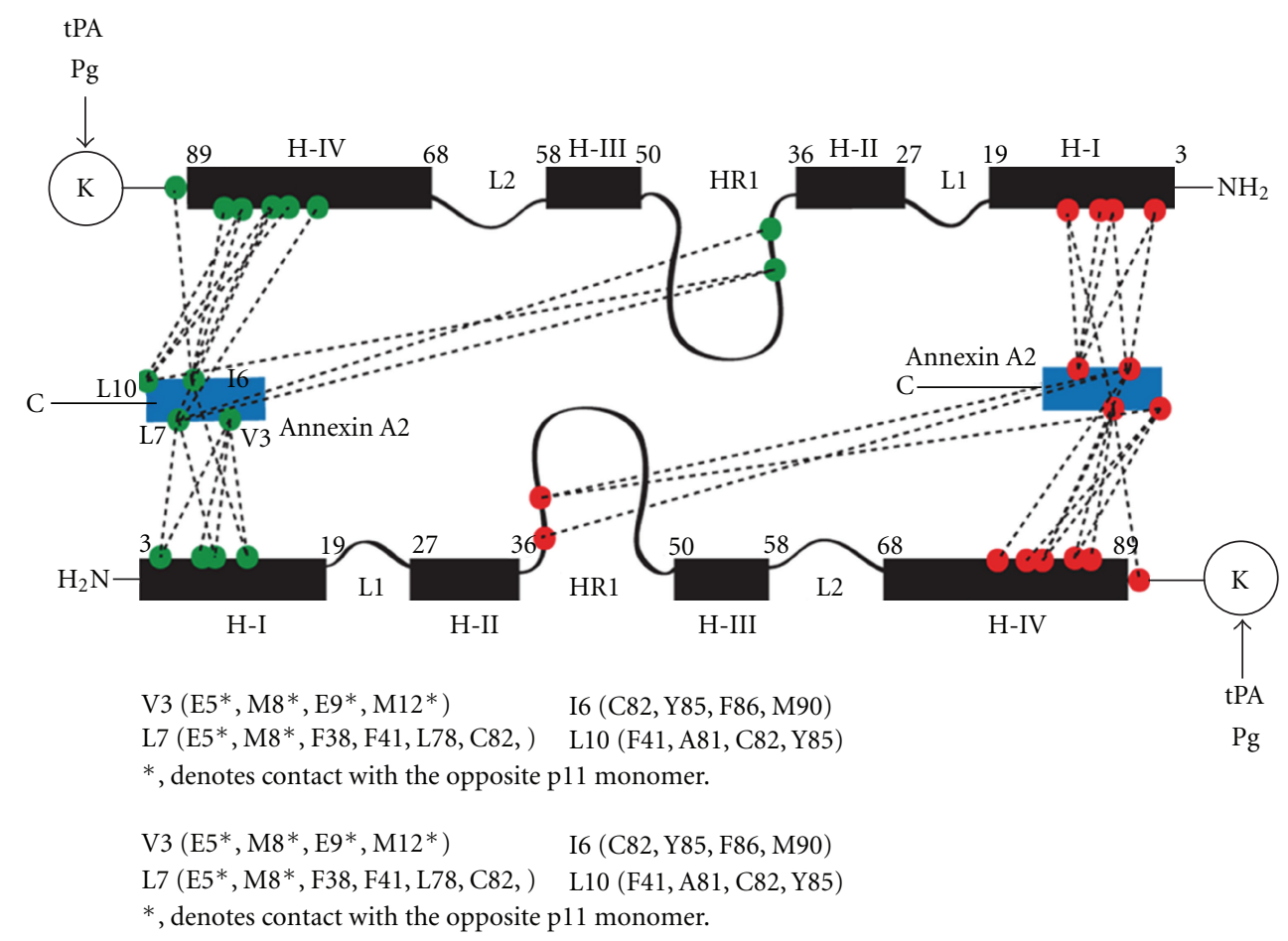

(a)

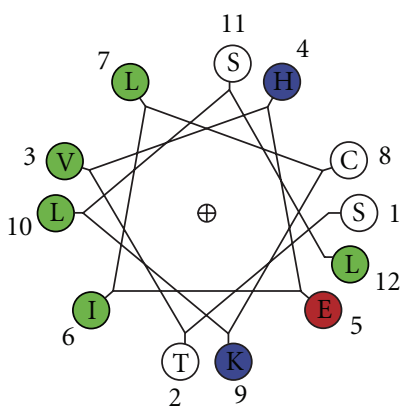

(b)

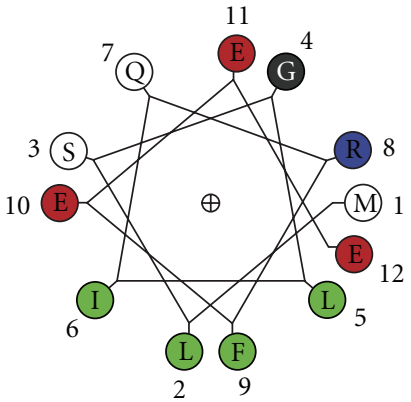

(c)

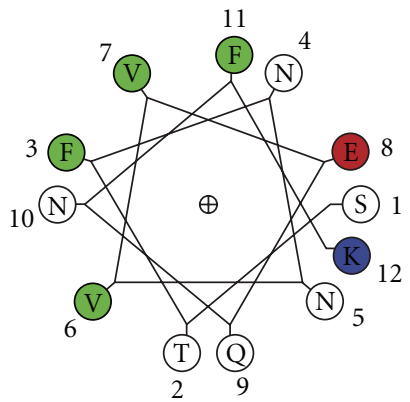

(d)

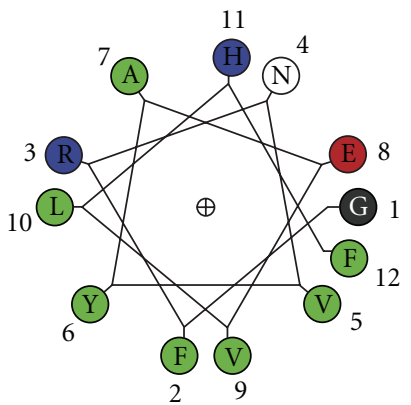

(e)

FIgURE 2: Structure of S100A10. A cartoon of the association of S100A10 with its two primary ligands, annexin A2 and plasminogen, is presented in $A$. The figure illustrates the structure of S100A10 and the association of S100A10 with the amino-terminus of annexin A2 and with plasminogen. Each S100A10 monomer is composed of four $\alpha$-helical domains H-I, H-II, H-III, and H-IV. Separating H-I and H-II helical regions is a loop, L1. The H-III and H-IV are separated by a second loop (L2). The H-II and H-III are connected by a flexible linker or hinge region (HR1). The points of interaction between the amino-terminus of annexin A2 and S100A10 are quite extensive and four hydrophobic amino acids of the amino terminus of annexin A2 (V3, I6, L7, and L10) form seven points of contact with helix H-I of one monomer, two points of contact with the hinge region, and nine points of contact with helix H-IV of the other monomer for a total of nineteen points of contact with S100A10. Shown also are the helical wheel projections for the S100A10-binding site for B, annexin A2; C, NS3; D, DLC1; E, TASK-1. The S100A10-binding region of these ligands consists of an amphipathic $\alpha$-helix in which hydrophobic residues form a binding site on one side of the helix. The program for helical wheel projections was obtained from http://www.kael.net/helical.htm.

van der Waals interactions with the residues of helix IV (S. Rety, personal communication).

Previous studies have shown that S100A10 binds both tPA and plasminogen through its carboxyl-terminal lysine [19]. Thus a binding site for tPA and plasminogen is present on each S100A10 monomer which contrasts with the annexin A2 binding site for S100A10 that requires the participation of both S100A10 monomers. Although the carboxyl-terminal extension of S100A10 plays an important role in the function of the protein, it is unclear if other amino acid residues other than the carboxyl-terminal lysine also participate in tPA or plasminogen binding. However, since removal of the carboxyl-terminal lysines of either S100A10 alone or S100A10 complexed with annexin A2 completely inhibited tPA and plasminogen binding, it is likely that the carboxylterminal lysine of S100A10 plays a key role in tPA and plasminogen binding $[15,20,63]$. As had been shown for many plasminogen-binding proteins, the carboxyl-terminal lysine 


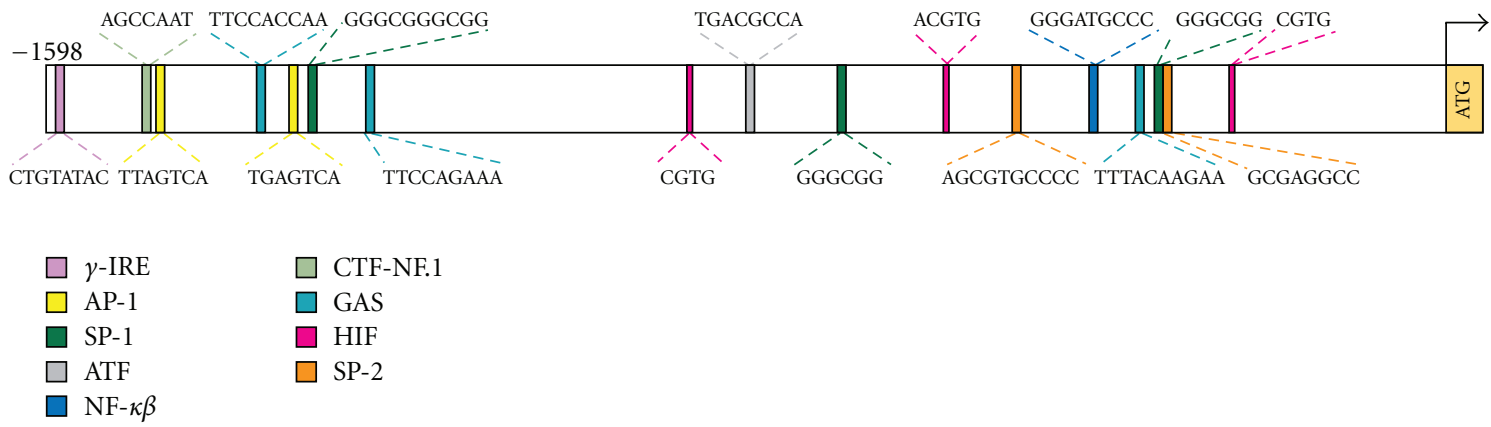

FIGURE 3: Schematic representation of the human S100A10 promoter. Transcription factor-binding sites are marked with color boxes.

forms a binding site for the lysine binding domains (kringles) of both tissue plasminogen activator (tPA) and plasminogen (reviewed in $[12,13,18,94]$ ). Figure 8 presents the amino acid sequence of several well-established plasminogen receptors. Although these receptors all possess carboxyl-terminal lysines it was interesting to note that several of the receptors also displayed a basic amino acid five residues distant from the carboxyl-terminal lysine, at a position corresponding to K91 in S100A10, suggesting that this residue may also play an important role in plasminogen receptors. Analysis of the phylogenetic distribution of S100A10 reveals that the carboxyl-terminal lysine is conserved across all species from human to fish (Figure 9). Only Xenopus S100A10 does not possess a carboxyl-terminal lysine. Interestingly, K91 (in the human S100A10 sequence) is absolutely conserved in all species examined. Whether this residue plays a role in maintaining the orientation of the carboxyl-terminal residue or directly participates in ligand binding is unclear. It is not unreasonable to suspect that K91 may influence the affinity of interaction between plasminogen and S100A10. The binding of annexin A2 to S100A10 increases the affinity of plasminogen binding to S100A10 by about ten fold, suggesting that the plasminogen binding to the carboxylterminal lysine of S100A10 is influenced by the conformation of S100A10 [63].

The other S100 family members that possess carboxylterminal lysines include S100A4, S100A5, S100A13, S100P, and S100Z. Interestingly, of these S100 proteins, plasminogen binding has only been reported for S100A4 [95]. As discussed, S100A10 is present in mammals, birds, reptiles, amphibians, and fish, but not in insects, nematodes, protozoa, fungi, or plants (Figure 9). Similarly, plasminogen, one of the established ligands of S100A10, is present in vertebrates including fish [96]. In contrast, S100A2, S100A7, S100A12, S100Z, and S100P are present in humans but not in mouse and rat [73]. The expression of S100A2, S100A3, S100A4, S100A5, and S100A6 is restricted to mammals and is absent in birds and fish [80]. Therefore, the presence of a carboxyl-terminal lysine has been highly conserved in the structure of S100A10 and appears to parallel the phylogenetic distribution of its ligand, plasminogen. Similarly the presence of the S100A10-annexin A2 complex in the swamp eel is consistent with the phylogenetic conservation of the annexin A2 binding site on S100A10 [97].

\section{Regulation}

S100A10 is expressed fairly ubiquitously in most cells and tissues yet its promoter region lacks a TATA box. Several binding motifs for various transcription factors have been identified within the promoter region of S100A10, such as binding sites for the transcription factor $\mathrm{Sp} 1$ [98]. Interferon (IFN) $-\gamma$ has been shown to induce S100A10 expression in epithelial cell lines through the transcription factor STAT1 [27] (Figure 3). STAT1-induced S100A10 expression was dependent on the presence of GAS sites in the S100A10 promoter region. The promoter region for S100A10 also contains glucocorticoid response elements (GREs) and glucocorticoid stimulation has been demonstrated to induce S100A10 expression [99-101]. S100A10 expression may additionally be induced by transforming growth factor- $\beta$ [26], gonadotrophin, epidermal growth factor, basic fibroblast growth factor, and interleukin $1 \beta[24,25,102]$. Decreases in S100A10 expression have been associated with increased risk of depression. Recently, S100A10 promoter hypermethylation has been demonstrated in studies using a rodent model of depression and hypermethylation of the S100A10 promoter region was reduced following administration of antidepressants, suggesting potential epigenetic regulation of S100A10 expression [103].

It was initially observed that depletion of annexin A2 resulted in a concomitant loss of cellular S100A10 and from this study it was inferred that the S100A10 homodimer was unstable in the absence of annexin A2 [104]. Subsequently, it was suggested that S100A10 was rapidly degraded by a proteosomal degradation mechanism [105]. Finally, it was observed that DLC1 decreased the cellular levels of S100A10 by binding to S100A10 which resulted in the displacement of annexin A2 from S100A10. Although annexin A2 and DLC1 bound to the similar site on S100A10, the binding of DLC1 to S100A10 did not protect S100A10 from ubiquitin-mediated degradation. Thus, the displacement of annexin A2 by DLC1 resulted in the ubiquitin-mediated degradation of S100A10 [69]. Conceptually, these experiments established the important regulatory role of annexin A2 in protecting S100A10 from ubiquitin-mediated degradation and identified a new mechanism of regulation of S100A10 by the expression of proteins such as DLC1 that displace annexin A2 from S100A10 and in doing so target S100A10 for destruction. 


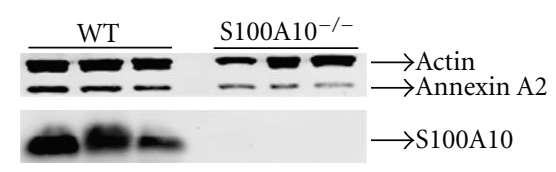

(a) Lung

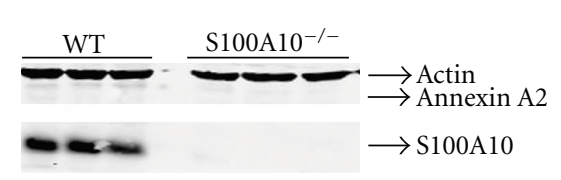

(b) Liver

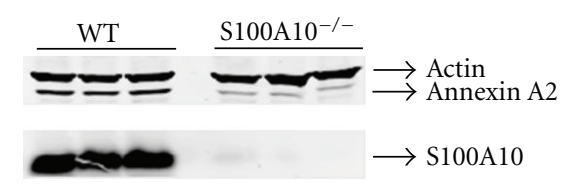

(c) Kidney

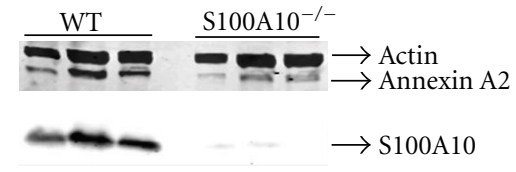

(d) Spleen

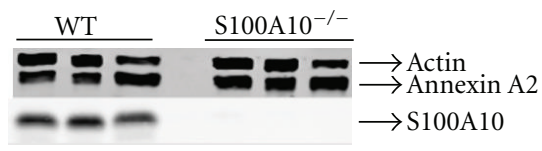

(e) Intestine

FIGURE 4: S100A10 and annexin A2 protein levels in tissues from S100A10 ${ }^{-/-}$mice. Annexin A2 and S100A10 protein levels were analyzed by Western blot in tissues isolated from wild-type (WT) and S100A10 ${ }^{-/-}$mice. Annexin A2 protein levels decreased in lung (a), kidney (c), and spleen (d), were not detectable in liver (b) and were unaltered in the small intestine (e). As expected, S100A10 protein levels were not detected in tissues isolated from $\mathrm{S} 100 \mathrm{~A} 10^{-1-}$ mice.

Other groups have demonstrated that annexin A2 may also stabilize S100A10 mRNA levels as loss of annexin A2 resulted in decreased S100A10 mRNA levels in MDA-MB-435 cells [106], melanocytes, and L5178Y murine lymphoma cells [107]. We have also detected S100A10 protein in murine liver in the absence of measurable annexin A2 (Figure 4). The mechanisms by which S100A10 is expressed and regulated posttranslationally by annexin A2 therefore appear to be celltype dependent.

As discussed, S100A10 is present on the extracellular cell surface as a complex with annexin A2, called AIIt [15]. The annexin A2 subunits of AIIt serve to anchor AIIt to the plasma membrane in a $\mathrm{Ca}^{2+}$-dependent fashion [108-110]. Several groups have reported that annexin A2 is required to transport S100A10 to the cell surface [111113]. Annexin A2, however, lacks a signal peptide which suggests that the transport to the cell surface occurs by an unconventional secretion pathway [114]. Others have shown that the transport of S100A10 to the cell surface requires the phosphorylation of annexin A2 [111-113]. More recently, Fang et al. described a mechanism by which IFN$\gamma$ stimulated expression of S100A10 results in increased S100A10 levels on the cell surface. They demonstrated that S100A10 transport to the cell surface is dependent on annexin A2 and utilizes the exosomal secretion pathway [28]. A model for the transport of S100A10 to the cell surface is presented in Figure 5.

\section{Cellular and Tissue Distribution}

S100A10 is present in the cell primarily with annexin A2 as part of the annexin A2/S100A10 heterotetrameric complex. This complex, called AIIt, is formed by the binding of two molecules of annexin A2 to the S100A10 homodimer. Annexin A2, which binds cellular membranes, serves as the membrane anchor for S100A10. Intracellular S100A10 participates in the trafficking of several plasma membrane proteins, including the 5-HT1B receptor [56], TRPV5 and TRPV6 [52, 89], TASK-1 [51, 115], and $\mathrm{Na}(\mathrm{V}) 1.8$ [54]. S100A10 present on the cell surface membrane as a complex with annexin A2 is a prominent plasminogen receptor and participates in tPA- and uPA-dependent plasminogen activation at the cell surface $[15,29,64-67]$.

Expression of S100A10 has been reported in a wide range of cell types and tissues. The expression of S100A10 protein is highest in lung, kidney, and intestine. S100A10 has also been observed in various cell types, including endothelial cells $[66,111]$, macrophages $[67,68,116,117]$, fibroblasts [37], epithelial cells [27, 89], and various cancer cell lines $[29,64,65,69,106,107,118-121]$. S100A10 is not detected in erythrocytes [37] and relatively low levels of S100A10 are found in the liver [122]. Our laboratory has shown the expression of S100A10 protein in murine lung, liver, kidney, spleen, and intestine (Figure 4). Interestingly, S100A10 appears to regulate annexin A2 protein levels in a tissue-specific fashion. We investigated annexin A2 protein and mRNA levels in tissues isolated from the S100A10-null mouse (Figure 6) and observed that the loss of S100A10 affected annexin A2 levels in a tissue specific fashion. While loss of S100A10 did not affect annexin A2 levels in the intestine, it resulted in decreased annexin A2 levels in the lung, liver, spleen and kidney. On the other hand, annexin A2 mRNA levels were not altered in any of the S100A10-null tissues (Figure 6). S100A10 therefore appears to contribute to annexin A2 protein stability in a tissue specific fashion.

\section{Function(s)}

6.1. Role As a Plasminogen Receptor. In order for a protein to be considered a plasminogen regulatory protein, several critical must be met. First, the putative plasminogen regulatory protein must bind plasminogen. Surface plasmon resonance studies have demonstrated that S100A10 binds plasminogen, $\left(\mathrm{K}_{\mathrm{d}}\right.$ of $\left.1.81 \mu \mathrm{M}\right)$, plasmin $\left(\mathrm{K}_{\mathrm{d}}\right.$ of $\left.0.36 \mu \mathrm{M}\right)$, and tPA $\left(K_{d}\right.$ of $\left.0.45 \mu \mathrm{M}\right)$. Furthermore, S100A10 possesses the requisite carboxy-terminal lysine that has been shown to be essential for plasmin activation at the cell surface. Removal of the carboxy-terminal lysines (carboxy-terminus of S100A10- [85]-Y-F-V-V-H-M-K-Q-K-G-K-K [96]) attenuates plasminogen and tPA binding [63]. Second, binding 


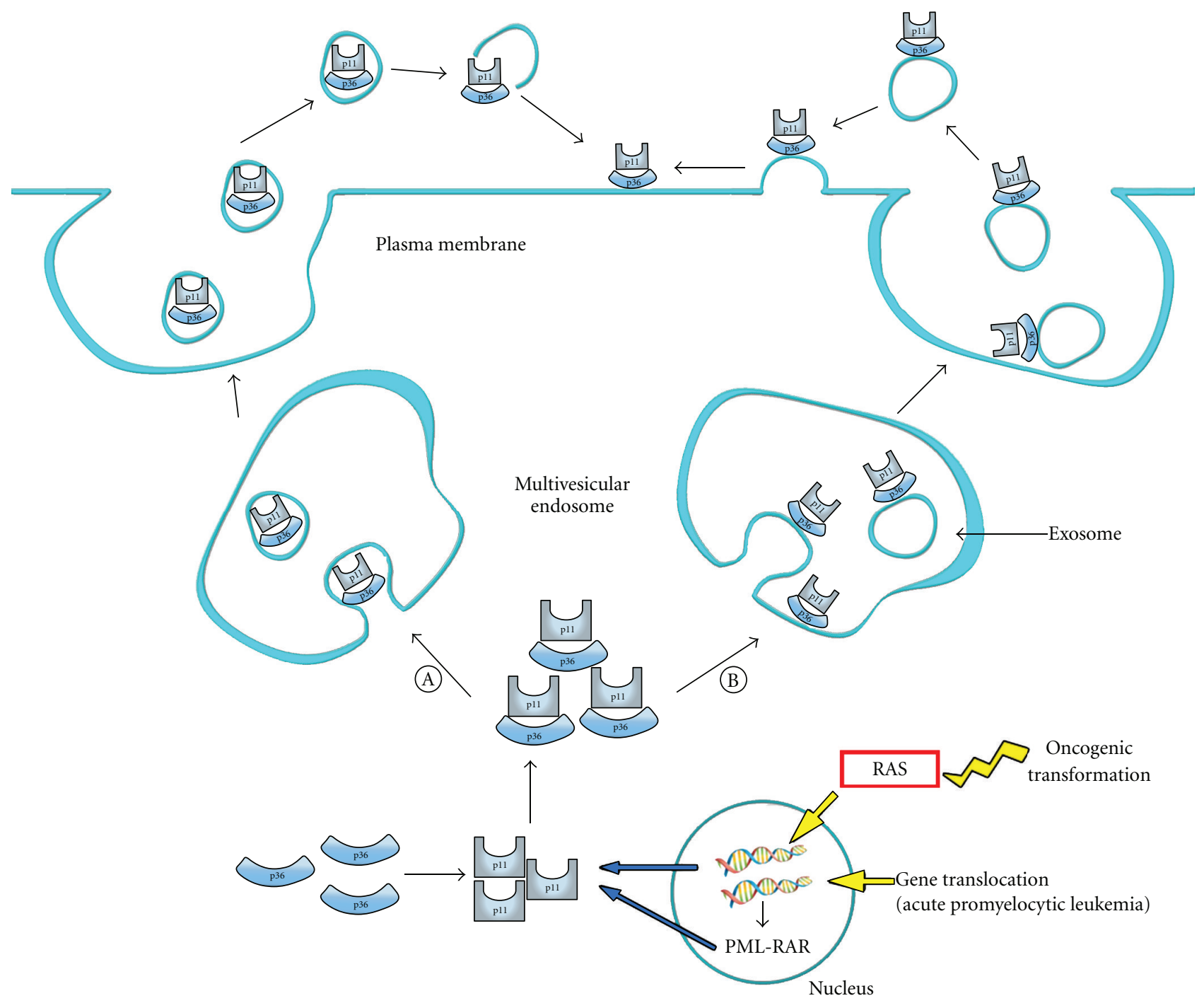

FIGURE 5: Regulation of the expression of extracellular S100A10. Many physiological agents (EGF, interferon- $\gamma$, transforming growth factor$\alpha$ ) and pathophysiological agents (PML-RAR $\alpha$ and KRas oncogenes) stimulate the upregulation of S100A10 protein levels. Annexin A2 is thought to play two important roles in the export of S100A10. First, the association of annexin A2 with S100A10 protects S100A10 from ubiquitin-mediated proteasomal degradation as S100A10 is rapidly degraded in the absence of annexin A2. Secondly, the binding of annexin A2 with S100A10 is thought to promote the capture of the complex by the exosomes. Exosomes are small vesicles, approximately $30-100 \mathrm{nM}$ in diameter, that are formed by the inward budding of large intracellular compartments called multivesicular endosomes (MVE). Proteins and RNA that are present in the cytoplasm are trapped within the lumen of the exosomes during this inward budding process and proteins that associate with the MVE lumenal membrane during MVE budding are localized to the outer surface of the exosomes. The exosomes, sequestered as intact vesicles within the MVE, are released from cells when the membrane of the MVE fuses with the plasma membrane. The association of annexin A2 with exosomes has been reported but it is unclear at this time if the S100A10/annexin A2 complex is present on the surface or in the lumen of the exosomes. In our speculative model, we show that S100A10 protein that is synthesized in response to oncogenic agents such as oncogenic Ras or the PML-RAR oncogene forms a complex with annexin A2. The S100A10/annexin A2 complex is then sequestered with the lumen of the exosomes during the inward budding of the MVE (A). These MVEs fuse with the plasma membrane resulting in the release of the exosomes into the extracellular space. These exosomes rupture and release the S100A10/annexin A2 complex from their lumen which then allows the association of the complex with the plasma membrane. Alternately, the S100A10/annexin A2 complex may be present on the lumenal surface of the MVE (B). The inward budding of the MVE results in the association of the S100A10/annexin A2 complex with the outer surface of the newly formed exosomes. The exosomes released by the fusion of the MVE with the plasma membrane fuse with the plasma membrane resulting in the incorporation of the S100A10/annexin A2 complex at the plasma membrane. 


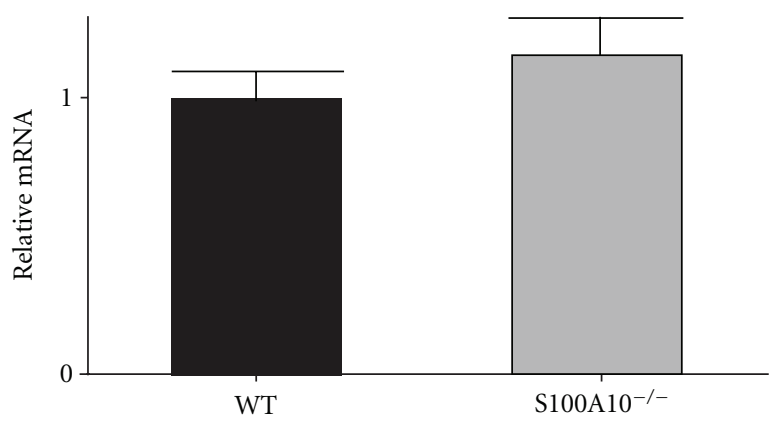

(a) Lung

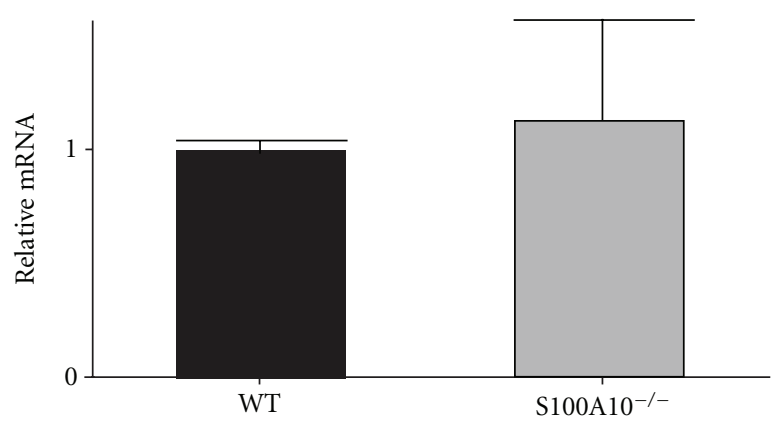

(b) Kidney

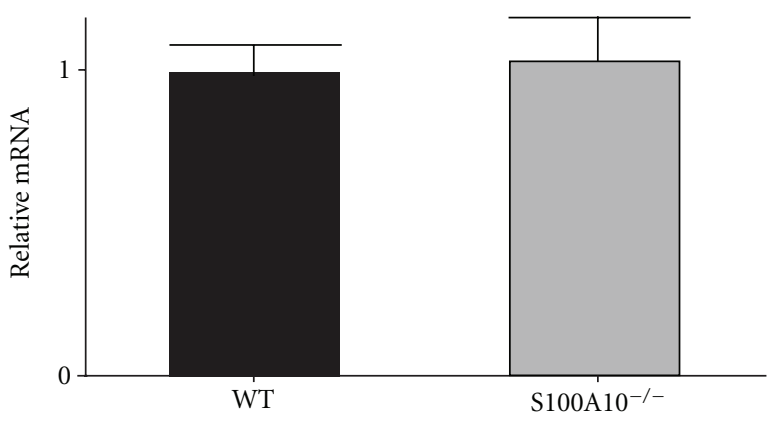

(c) Spleen

FIGURE 6: Annexin A2 mRNA levels in tissues from S100A10 ${ }^{-/-}$mice. Annexin A2 mRNA levels were analyzed in tissues isolated from WT and S100A10 $0^{-/-}$mice. Loss of S100A10 did not affect annexin A2 mRNA levels in lung (a), kidney (b), and spleen (c). Statistical analysis was performed using Student's $t$-test and the data are expressed as the mean $( \pm)$ SEM of 6 independent experiments.

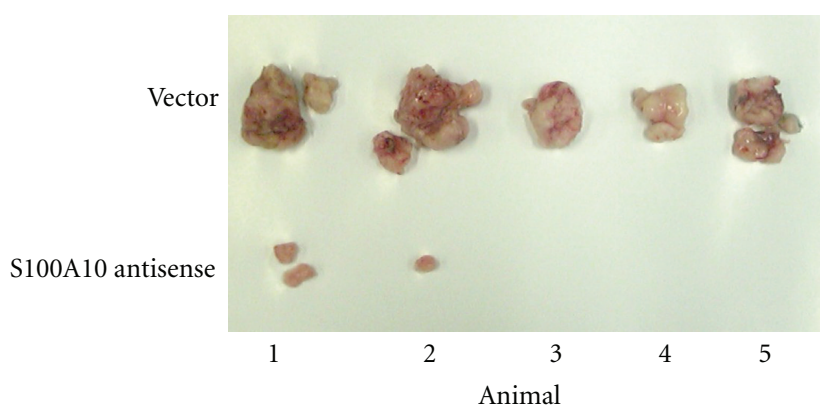

(a)

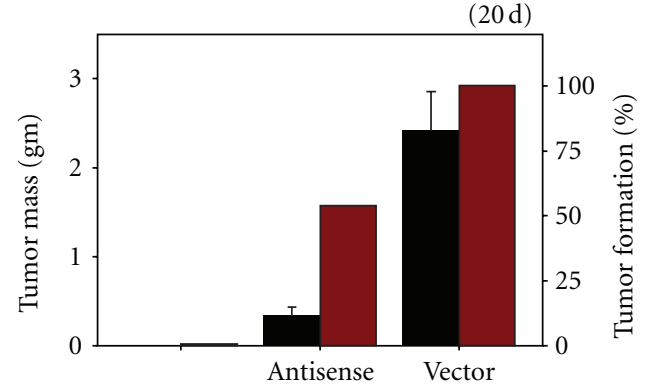

Tumor mass

Animals that formed tumors after implantation (\%)

(b)

FIGURE 7: Role of S100A10 in Tumor Formation. HT1080 fibrosarcoma cells (106 cells) were injected intradermally into SCID mice and dissected and weighed after 20 days. Thirteen mice were used in each group. The dissected-20 day tumors were photographed. $7 / 13$ of mice injected with S100A10 antisense HT1080 cells developed tumors compared to 100\% tumor development for the WT HT1080 cells. Furthermore, the tumors grown by the S100A10-depleted HT1080 cells were much smaller. The data shows that the loss of S100A10 from the cancer cell surface and the resultant loss of protease activity inhibited tumor growth.

of plasminogen to the candidate regulatory protein must convert plasminogen into the open, activation-susceptible conformation. Studies using plasminogen that was FITC labeled at its active site showed that addition of either AIIt or S100A10 alone, but not annexin A2 alone, resulted in quenching of the fluorescence of plasminogen, meaning that S100A10 promoted an open, activatable conformation of plasminogen [19]. Third, the plasminogen receptor should be inactivated by removal of its carboxyl-terminal lysine. S100A10 is a high affinity substrate for several carboxypeptidases, which have been shown to block cellular plasminogen activation by cleaving carboxy-terminal lysines [7]. Our laboratory has demonstrated that carboxypeptidase $\mathrm{B}(\mathrm{CpB})$ ablates enhancement of plasminogen activation 


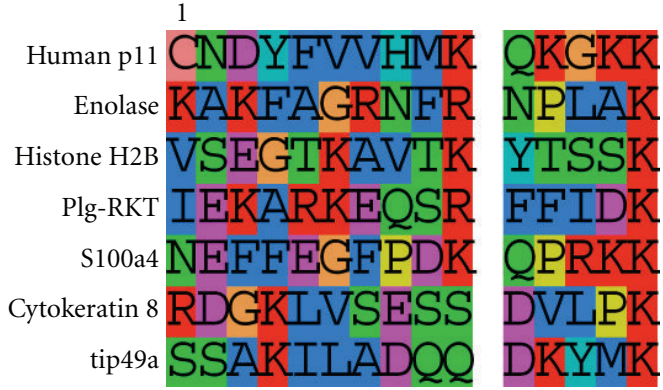

Figure 8: Plasminogen receptors.

by homodimeric S100A10 or by the S100A10/annexin A2 complex through removal of carboxy-terminal lysines of S100A10 [20]. Fourth, binding of plasminogen regulatory proteins to plasmin or plasminogen activators must protect these enzymes from inactivation by their inhibitors. S100A10 has been shown to protect tPA and plasmin from PAI-1 and alpha2-antiplasmin, respectively [15]. Fifth, although not a criterion for a plasminogen receptor per se, it is expected that in order for a plasminogen receptor to efficiently convert plasminogen to plasmin it should bind to or colocalize with plasminogen activators. S100A10 binds directly to tPA and colocalizes with uPAR on the cell surface. Studies from our laboratory have demonstrated the presence of UPAR in S100A10 precipitates and colocalization has been observed by immunofluorescence microscopy $[15,64,65]$. Sixth, depletion of the plasminogen receptor from the cell surface should result in a loss in cellular plasmin generation. The loss of S100A10 from the cell surface results in a loss of cellular plasmin generation. In vitro studies have demonstrated that when HT1080 fibrosarcoma cells were transfected with antisense S100A10, resulting in depletion of S100A10 but not annexin A2, plasmin production was reduced by $95 \%$ and extracellular matrix hydrolysis was decreased by almost $70 \%$ in comparison to the vector controls. Furthermore, tumor formation in SCID mice was dramatically reduced in S100A10-antisense-transfected cells compared to the vector control (Figure 7). Taken together, this evidence supports a key role for $\mathrm{S100A10}$ in plasmin regulation and in the process of oncogenesis.

6.2. S100A10 in Fibrinolysis. Increasing evidence has shown that the plasminogen receptor, $S 100 \mathrm{~A} 10$, is a main regulator of plasmin activity at the surface of endothelial cells playing a main role in vascular fibrinolysis. Our laboratory recently used a human microvascular endothelial cell line, called telomerase immortalized microvascular endothelial (TIME) cells [123], to investigate the role of S100A10 in fibrinolysis [66]. We used an shRNA system to deplete these cells of S100A10 and observed a significant impairment in both plasminogen binding (50\%) and plasmin generation (60\%) even though the cell surface levels of its binding partner annexin A2 were identical in the S100A10-depleted cells compared to the control cells expressing a scramble shRNA [66]. On the other hand, annexin A2-depleted TIME cells showed similar losses in plasminogen binding and plasmin generation as the S100A10-depleted TIME cells [66]. Taking into consideration that the annexin A2-depleted TIME cells were also depleted of S100A10, we concluded that the loss of cell surface annexin A2 did not affect plasminogen binding or plasmin generation in these endothelial cells. In view of these results we have proposed that annexin A2 functions to stabilize S100A10 protein levels and to localize S100A10 to the cell surface of endothelial cells, while S100A10 is directly responsible for plasminogen binding and plasmin generation by endothelial cells [12].

The role of S100A10 in fibrinolysis in vivo has been recently established using the S100A10-null mouse model. These studies showed an enhanced accumulation of fibrin in the S100A10-null mice tissues compared to wild-type mice litter mates. These studies initially demonstrated that the enhanced fibrin deposition observed in the S100A10null mice tissues was not due to increased coagulation, since PT (prothrombin time) and aPTT (activated partial thromboplastin time) assays, which directly measure coagulation, were identical for both the WT and the S100A10null mice [66]. In order to directly investigate fibrinolysis in the S100A10-null mice, we used a novel approach which involved the injection of the snake poison, batroxobin, in S100A10-null and WT mice. Batroxobin is a thrombinlike enzyme that rapidly cleaves fibrinogen resulting in the production of fibrin microclots which are removed from the vasculature through the process of fibrinolysis. We then compared the ability of these mice to dissolve the batroxobin-induced blood clots. This experiment showed that the S100A10-null mice have significantly lower rates of fibrinolysis of the batroxobin-induced blood clots in vivo compared to the WT mice [66]. Finally, a tail clip experiment showed that mice lacking S100A10 have an approximately 4 -fold reduction in the time required for the cessation of bleeding compared to the WT mice. This is most likely due to decreased fibrinolysis of the tail clip-induced blood clot by the S100-null mice. Therefore, a central defect in the S100A10-null mice involves plasmin generation by the endothelium. These studies taken together establish that S100A10 plays a major role in fibrinolysis in vivo.

To investigate if S100A10 plays a significant role in angiogenesis in vivo, we used a well-established method where Matrigel (which mimics the extracellular matrix) is injected in mice allowing for the measurement of the angiogenic response towards a growth factor stimulus in vivo [66]. This study showed a defective vascularization of the Matrigel plugs in the S100A10-null mice compared to the WT mice, establishing that S100A10 plays an important role in angiogenesis in vivo. These results were further supported by another experiment that showed that S100A10-depleted endothelial cells have a significantly decreased ability to migrate through Matrigel barriers. In conclusion, the studies performed using the S100A10-null mouse model clearly established an important role for S100A10 as a positive regulator of fibrinolysis and angiogenesis.

6.3. S100A10 in Signalling. S100A10, as part of AIIt, has also been shown to function as a receptor in plasmin-induced 

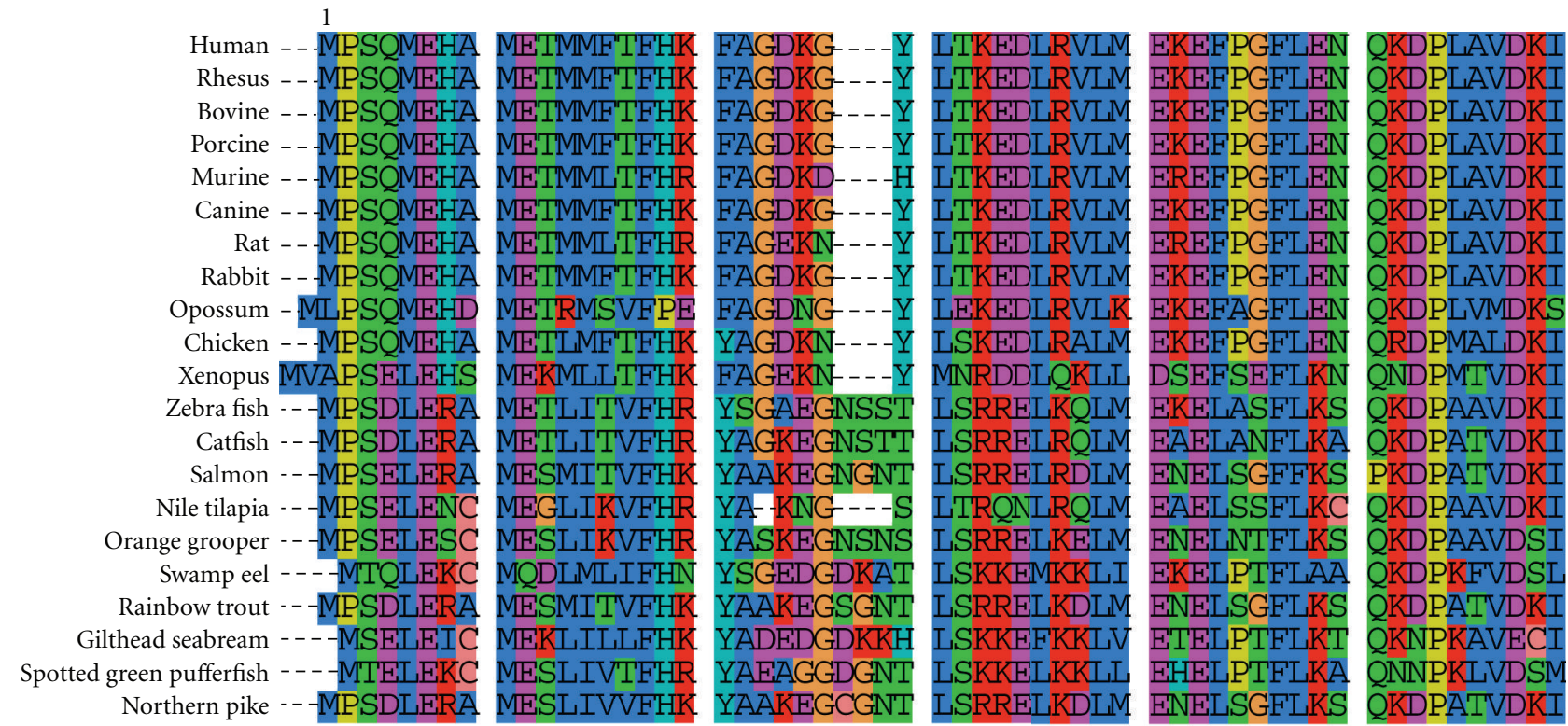

61
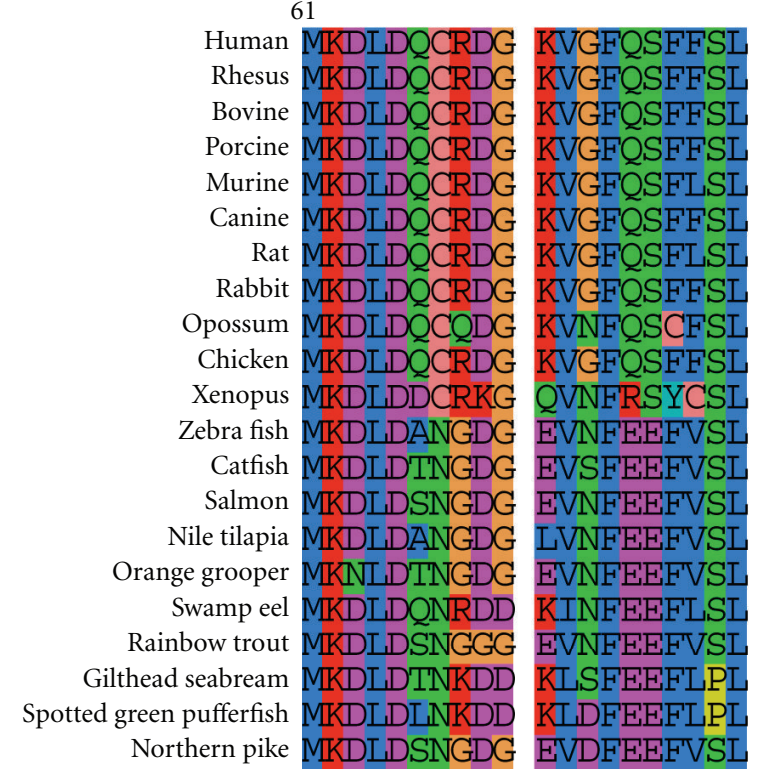

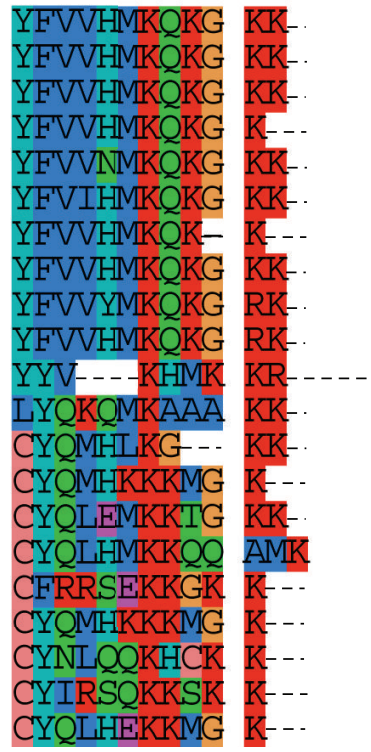

Figure 9: S100A10 phylogeny.

signaling in monocytes [124] and macrophages [125]. After having demonstrated that monocytes show a chemotactic response to plasmin that is dependent on S100A10 and annexin A2 [124], the Simmet group showed that plasmin, through S100A10 and annexin A2, activates macrophages by a mechanism involving stimulation of the Janus kinase JAK1/TYK2 signaling pathway. JAK1/TYK2 leads to STAT3 activation, Akt dependent NF- $\kappa \mathrm{B}$ activation and phosphorylation of extracellular signal-regulated kinase 1/2 (ERK1/2) and mitogen-activated kinase, p38. Plasmin also triggered nuclear translocation of STAT3 and p65 transcription factors and the induction of the proinflammatory cytokines tumor necrosis factor- $\alpha$ and interleukin-6. The Simmet group has proposed a mechanism by which plasmin cleaves annexin A2 at lysine 27 (K27), resulting in disruption of AIIt at the cell surface and transduction of a signaling cascade inside the cell. Further work needs to be performed to identify a more complete mechanism by which AIIt serves as a signaling receptor and transduces this signal into the cell.

\section{Role of S100A10 in Disease}

7.1. S100A10 in Depression. S100A10 is expressed in several regions of the brain and through its interactions with 5HT1B receptors and NaV1.8/ASIC-1 channels, the involvement of S100A10 in the regulation of depression-like states and nociception has been thoroughly examined $[53,54,56]$. 5-HT1B receptors modulate serotonin neurotransmission by 
acting as both autoreceptors on serotonin-containing neurons originating from the raphe nuclei and heteroreceptors on several neurons that do not contain serotonin $[126,127]$. 5 -HT1B receptors have been demonstrated to play a role in the pathophysiology of multiple mental disorders, including depression $[128,129]$.

S100A10 levels are decreased in a mouse model of depression and in brain tissue from unipolar depressed patients. The S100A10-null mice demonstrate significantly reduced responsiveness to stimulation of 5-HT1B receptors in biochemical, electrophysiological, and behavioural tests thus providing strong evidence to suggest that the interaction between S100A10 and 5-HT1B receptors plays a role in the pathophysiology of depression-like states. Further evidence suggests that decreased levels of S100A10 correlate with greater susceptibility to depression [56]. The S100A10-null mouse demonstrate a reduced number of 5-HT1B receptor ligands which are likely mediated by multiple mechanisms, such as altered recruitment of the receptors to the cell membrane or disturbed endosomal recycling and/or degradation of the receptor. In contrast, overexpression of S100A10 leads to an increase in the number of 5-HT1B receptors at the cell surface and recapitulates certain behaviors seen after antidepressant treatment in mice [56]. Similarly, administration of antidepressants increases S100A10 expression in the brain [130].

In addition to results seen at the cellular level, the S100A10-null mouse exhibits a depressive-like phenotype in which they display a decreased thigmotaxis and increased immobility in tail suspension tests in response to imipramine [56]. Taken together, these results show that S100A10 plays an important role in the dynamic modulation of 5-HT1B receptor function and that decreased expression of S100A10 leads to a depressive-like state.

\subsection{S100A10 in Inflammation}

7.2.1. S100A10 Regulates Plasminogen-Dependent Macrophage Invasion. It has been shown that the cell surface generation of plasmin is required for macrophage recruitment to a site of inflammation and that macrophage recruitment is mediated in part through the plasmin-dependent activation of MMP-9 [131]. Therefore, macrophage-generated plasmin plays two roles in invasion; it directly hydrolyzes extracellular matrix (ECM) proteins and it activates MMP9, thus promoting further ECM degradation. Analysis of the plasminogen receptors on the surface of macrophages has identified $\alpha$-enolase, histone H2B, and Plg-RKT as plasminogen receptors that participate in macrophage invasion [7, 132-134]. Recent studies performed by our laboratory investigated the mechanism of plasminogen-dependent inflammatory cell recruitment in vivo using two different methodologies: the thioglycollate-induced peritonitis and the Matrigel plug assay [67]. We observed that in response to thioglycollate-induced peritonitis, macrophage migration through the peritoneal membrane into the peritoneal cavity of the S100A10-null mouse was reduced by about 53\%. Our results with the Matrigel plug assay demonstrated that S100A10-null macrophages had a limited capability to infiltrate into the Matrigel plug in vivo. Analysis of the mechanism of macrophage migration through the Matrigel suggested that S100A10-null macrophages have a reduced capacity to generate plasmin and activate MMP-9. Therefore, the simplest explanation to our results is that S100A10 and other carboxyl-terminal plasminogen receptors contribute to macrophage plasmin generation that is utilized for ECM hydrolysis and MMP-9 activation. Of note was our observation that neutrophil recruitment to the peritoneal cavity in response to a thioglycollate-dependent inflammatory stimulus was also regulated by S100A10. It has been reported that neutrophil recruitment in plasminogen-null mice is identical to that of wild-type mice [135] suggesting that plasmin does not play a role in neutrophil recruitment in the thioglycollate model. We are currently investigating the possibility that S100A10 may regulate proteases other than plasmin on the surface of the neutrophil. For example, it has been reported that S100A10 regulates the activation of cathepsin B on the surface of certain cancer cells [90].

Previous studies have established the presence of S100A10 and its binding partner, annexin A2, on the surface of murine macrophages [136]. These studies showed that knockdown of annexin A2 resulted in decreased plasmin generation, matrix remodeling, and a dramatic loss in directed migration [137]. However, since annexin A2 knockdown results in concomitant loss of S100A10, it is difficult to attribute these effects to either annexin A2 or S100A10. Annexin A2 levels were reduced in macrophages isolated from S100A10-null mice, making it unclear if the reduced macrophage migration in response to thioglycollate-induced peritonitis was due to the loss of S100A10 or annexin A2 or both. Elucidating the role that annexin A2 plays in invasion is complicated by the reports from three laboratories that intact annexin A2 does not bind plasminogen $[63,133$, 138]. Since annexin A2-dependent plasmin generation is blocked by the lysine analog $\varepsilon$-amino caproic acid or by treatment of annexin A2 by carboxypeptidase-B [138], it has been proposed that annexin A2 binds plasminogen upon proteolytic cleavage of the protein and exposure of a new carboxyl-terminal lysine [138]. Further proof that plasminogen binding to annexin A2 requires "activation" by a carboxyl-terminal cleavage event was provided by the report that the K307T mutant annexin A2 transfected into HEK 293 cells failed to bind plasminogen while a change of a lysine proximal to this site (K328I) bound plasminogen with similar affinity to the wild type [139]. The proteinase that has been proposed to cleave annexin $\mathrm{A} 2$ has not been identified but plasmin has been ruled out [139]. We addressed the issue of whether annexin A2 processing occurred in migrating macrophages in vivo by examining the molecular mass of cell surface annexin A2 by SDS-PAGE [67]. The macrophages used in this study were isolated from the peritoneal cavity of thioglycollate-stimulated mice. We have recently shown that the loss of the carboxyl-terminal 29 amino acid of annexin A2 (Ser1-Asp338) generates a truncated form of annexin A2 (Ser1-Lys307), that is easily detected on SDS-PAGE [14]. However, macrophage cell surface annexin A2 is similar in molecular mass to 
unproteolyzed annexin A2. Since the macrophages isolated for these studies were macrophages that had migrated through the extracellular matrix into the peritoneal cavity and were therefore proteolytically active, this result suggests that macrophage cell surface annexin A2 is not cleaved and therefore does not participate in plasminogen binding, plasmin generation, or macrophage invasion. Similarly, it has been reported that annexin A2 is not proteolyzed during active plasmin generation by HT1080 cells [64]. It was also interesting that S100A10 and annexin A2 protein levels were higher in thioglycollate-stimulated peritoneal macrophages compared to resident peritoneal macrophages, suggesting that macrophages upregulate S100A10 after activation by inflammatory mediators.

Our observation that annexin A2 levels were lower in macrophages isolated from S100A10-null mice compared to WT mice was unexpected. RT-PCR analysis suggested that the annexin A2 mRNA levels were similar in these macrophages [67]. S100A10 has been shown to be ubiquitinated $[105,140]$ and rapidly degraded by the proteasome. The binding of S100A10 to annexin A2 protects S100A10 from ubiquitination and proteasomal degradation. In contrast, although annexin A2 is ubiquitinated, ubiquitination does not activate the proteasomal degradation of the protein [141]. We have also observed that the proteasomal inhibitor, MG-132, does not affect the annexin A2 levels thereby eliminating proteasomal degradation as a possible regulatory mechanism for annexin A2 [29]. However, it is known that annexin A2 is mainly cytosolic whereas the annexin A2S100A10 complex is associated with the cytoskeleton [39, 142]. Since the turnover of cytoskeleton-bound annexin A2 $(t 1 / 2=40-50 \mathrm{~h})$ is three to four times slower than for the cytoplasmic annexin A2 $(t 1 / 2=15 \mathrm{~h})$ [37], it is possible that changes in the subcellular distribution of annexin A2 in the S100A10-null macrophages could account for the decreased annexin A2 levels.

7.3. S100A10 in Oncogenesis. Oncogenesis, the process of tumor development and progression, requires an intimate association between the cancer cells and the tumorassociated cells. The cancer cells utilize plasmin and other proteases such as cathepsin B and the matrix metalloproteases (MMPs) to proteolyse the extracellular matrix and basement membrane in order to gain access to the circulation. Once in the circulation, the cancer cells utilize proteolytic activity to enter and form stable metastatic foci in other tissues. The tumor-associated cells such as macrophages also require proteolytic activity in order to migrate from the circulation into the tumor stroma. Therefore, proteolytic activity is used by both cancer cells and tumor-associated cells during oncogenesis. Several studies have established that plasmin is an important protease involved in cancer cell migration and invasion, but the plasminogen receptor(s) that is involved in the regulation of plasmin activation during oncogenesis remains elusive.

The uPA receptor, uPAR, is an important regulator of plasmin-dependent extracellular matrix proteolysis in cancer cells. uPAR binds uPA and its zymogen form, pro-uPA, and therefore localizes these proteins to the cell surface
[143]. Activated uPA that is bound to the uPAR at the cell surface cleaves plasminogen and the resultant plasmin reciprocally cleaves and activates pro-uPA (Figure 1). This positive-feedback loop is further amplified by the increased concentration of the active and zymogen forms of uPA and plasmin at the cell surface through uPA or pro-uPA binding to the uPAR and plasminogen or plasmin binding to the plasminogen receptor(s) (reviewed in [144-146]). Previous work from our laboratory has shown that S100A10 colocalizes with UPAR and positively regulates the conversion of pro-uPA to active uPA [65]. The activation of proteases at the cell surface of cancer cells plays an important role in the migration of primary tumor cells as well as in the invasiveness of these cells and establishment of metastatic foci at other sites.

Several studies have shown that S100A10 plays an important role in tumor invasion and metastasis. Choi and colleagues have shown that mice injected with S100A10depleted HT-1080 fibrosarcoma cells have a 3-fold decrease in the number of metastatic foci in the lungs compared to mice injected with control HT1080 cells, while overexpression of S100A10 in the HT-1080 cells leads to a 16fold increase in the number of lung metastasis in these mice [64]. Furthermore, tumor formation in SCID mice was dramatically reduced in S100A10-antisense-transfected HT-1080 cells compared to the vector control (Figure 7). These results show that the ability of HT-1080 tumor cells to extravasate and metastasize is directly related to the extracellular expression of S100A10. Another study showed that siRNA-mediated downregulation of S100A10 gene expression in CCL-222 colorectal cancer cells resulted in a significant decrease in extracellular S100A10 protein, which correlated with a $45 \%$ loss in plasminogen binding and a $65 \%$ loss in cellular plasmin generation in these cells compared to the control cells. S100A10 depletion in CCL-222 cells also abolished the plasminogen-dependent invasiveness of these cells through a matrigel barrier. A remarkable observation made by this study was that the CCL-222 cells do not express annexin A2 on their extracellular surface and for this reason the plasminogen binding, plasmin activation and invasiveness of these cells, although dependent on the presence of S100A10 at the cell surface, were independent of annexin A2. Collectively, these studies establish a role for S100A10 as an oncogenic plasminogen receptor, involved in invasiveness and metastasis of cancer cells.

\subsection{The Role of S100A10 in the Migration of Macrophages to the Tumor Site. Inflammatory cell recruitment to the tumor microenvironment is indispensable to cancer progression. Tumor-associated macrophages (TAMs) represent a promi- nent component of the inflammatory cell population with solid tumors and density of TAMs within a tumor correlates with poor prognosis [147]. The recruitment of TAMs to the tumor microenvironment involves the migration of monocytic precursor cells from the circulation in response to various chemotactic signals originating from the tumor [148]. TAMs promote tumor growth by mediating inflam- mation, stimulating angiogenesis, suppressing antitumor immunity, and by matrix remodeling [149]. However, little}


is known about the proteolytic mechanism by which monocytes/macrophages migrate from the circulation to the tumor site. Several studies have hypothesized that macrophages mobilize a number of cell surface plasminogen receptors to generate plasmin thereby facilitating proteolysis of basement membrane and extracellular matrices to allow migration to the tumor site. Recently, O'Connell et al. [67] demonstrated that S100A10 plays a significant role in mediating plasmin generation at the surface of macrophages.

Phipps et al. [68] recently demonstrated that S100A10 plays a significant role in oncogenesis. Wild-type and S100A10-null mice were injected with Lewis Lung carcinoma cells and the kinetics of tumor growth was measured. Interestingly, tumors grown in the S100A10-null mice reached maximum size after seven days whereas tumors in their wild-type counterparts continued to grow exponentially. Upon termination of the experiment, LLC tumors from wild-type mice were 10-fold larger than those in S100A10null mice. Immunohistochemical analysis of the tumors revealed that macrophage recruitment was impaired in the S100A10-null mice. Macrophages were visible throughout wild-type tumors but were only found at the tumor edge in S100A10-null mice. Cytokine levels were similar in wild-type and S100A10 tumors thus eliminating the possibility that less macrophages were recruited due to impaired chemokine/cytokine production. Peritoneal injection of wild-type macrophages into S100A10-null mice prior to injection of LLC cells rescued tumor growth to levels comparable to those seen in wild-type mice, indicating that S100A10-null plays an important role in both angiogenesis and tumor growth in terms of macrophage function. Taken together, these studies demonstrated that expression of S100A10 on the surface of murine macrophages plays significant role in their ability to associate with the tumor microenvironment and, in turn, promotes tumor growth and progression, that is, oncogenesis.

7.5. Regulation of S100A10 by the Oncogene PML-RAR $\alpha$. Leukemia is a group of hematological malignancies characterized by clonal expansion of hematopoietic cells with uncontrolled proliferation, blocked differentiation, and decreased apoptosis. Acute myeloid leukemia (AML) is the most common leukemia affecting adults. Acute promyelocytic leukemia (APL) is a subtype of acute myeloid leukemia that is characterized by fusion of the retinoic acid receptor alpha (RAR $\alpha$ ) gene with the promyelocytic leukemia (PML) gene via the $t(15 ; 17)$ translocation, resulting in the expression of a PML-RAR $\alpha$ fusion protein [150]. Intracellular accumulation of the PML-RAR $\alpha$ fusion protein causes the inhibition of cellular differentiation of these cells into granulocytes, resulting in the accumulation of the abnormal promyelocytes in the bone marrow. Pathogenesis of the disease includes disseminated intravascular coagulation (DIC), fibrinolysis, and proteolysis. The excessive fibrinolysis and proteolysis is thought to be a result of increased production of the fibrinolytic enzyme plasmin, and clinical evidence supports this idea. It is common for patients with new diagnoses of APL to present with elevated D-dimer level, fibrin split products, elevated prothrombin time and partial thromboplastin time, and hypofibrinogenemia [151-153]. Because activation of plasmin at the cell surface is necessary for plasmin activity, attention has turned to elucidating the plasminogen receptor on APL cells.

Previous work has shown that annexin A2 levels are elevated in APL and annexin A2 protein levels have been implicated as the cause for the excessive fibrinolysis that is associated with the disease. It was previously observed that all-trans retinoic acid (ATRA) treatment of APL primary cells and cell lines resulted in loss of cell surface annexin A2. In vitro treatment of $\mathrm{t}(15 ; 17)$-positive APL cells with all-trans-retinoic acid significantly reduced both the cellular expression of annexin A2 and plasmin generation over a similar period $[154,155]$. However, since annexin A2 knockdown results in concomitant loss of S100A10, it is difficult to attribute these effects to annexin A2 or S100A10.

Of the reputed plasminogen receptors, annexin A2 was reported to be present at abnormally high levels on APL cells and it was proposed that the elevated levels of annexin A2 were responsible for increased production of plasmin and the hemorrhagic complications of APL. A recent publication from our laboratory examined the role of S100A10 in regulating the generation of plasmin at the surface of APL cells in NB4 cells [29]. We used the human APL cell line, NB4, for these studies. NB4 cells possess the $t(15 ; 17)$-translocation and constitutively express the PML-RAR $\alpha$ oncoprotein and are induced to terminally differentiate to neutrophils with ATRA. Depletion of S100A10 by RNA interference resulted in a $70 \%$ loss in plasminogen binding and a $64 \%$ loss in plasmin generation by the NB4 cells. Furthermore, depletion of S100A10 resulted in $60 \%$ fewer NB4 cells migrating through a fibrin barrier. These results established the importance of S100A10 in plasmin generation in promyelocytic leukemia cells. Treatment of the NB4 cells with ATRA resulted in a rapid reduction in the PML-RAR $\alpha$ oncoprotein concomitant with a loss of S100A10. ATRA treatment also resulted in a $60 \%$ loss in plasminogen binding, a $40 \%$ loss in plasmin activity, and a $60 \%$ loss in migration of the ATRA-treated NB4 cell through the fibrin barrier. The complete loss of cellular levels of S100A10 after ATRA treatment presents the possibility that the remission of hemorrhagic complications observed during treatment of APL patients with ATRA could be due to the ATRA-mediated loss of S100A10 from the surface of the leukemic promyelocytes.

Since the treatment of NB4 cells with ATRA is known to result in the upregulation of about 119 genes as well as the downregulation of 17 genes [156], it was unclear if the regulation of S100A10 by ATRA was directly regulated by the PML-RAR $\alpha$ oncoprotein or by other ATRA-regulated genes. This issue was directly addressed by examining S100A10 levels in the U937/PR9 cells, which express PMLRAR $\alpha$ oncoprotein under the control of a zinc-inducible promoter. Expression of PML-RAR $\alpha$ oncoprotein resulted in a rapid and dramatic upregulation of S100A10 protein and a subsequent increase in plasminogen binding and fibrinolytic activity. We also observed that annexin A2 was upregulated by induced expression of the PML-RAR $\alpha$ oncoprotein. However, when the PML-RAR $\alpha$ oncoproteinexpressing PR9 cells were depleted of S100A10 by RNA 
interference, we observed a dramatic loss of plasminogen binding and plasmin generation [29]. These data suggest that PML-RAR $\alpha$ oncoprotein increases the S100A10 protein levels and also implicate S100A10 as a major component of the fibrinolytic system upon development of APL. Therefore, the upregulation of S100A10 at the cell surface of promyelocytic leukemic cells is likely the cause of the bleeding complications that are associated with APL.

These results demonstrated, for the first time, the regulation of S100A10 protein levels by an oncogene. A study performed by Sloane's laboratory showed that disruption of the gene that encodes oncogenic K-Ras, a well established oncogene, results in a dramatic decrease in S100A10 protein levels [157]. This result suggests that S100A10 protein levels might also be stimulated by oncogenic Ras and that S100A10 might play a role in Ras-dependent plasmin activation and, consequently, cancer cell invasiveness. Nevertheless, further studies are necessary in order to address this hypothesis.

\section{Summary}

The evidence that has accumulated over the past 15 years supports the concept that one of the most important physiological functions of S100A10 is as a plasminogen receptor. As such, S100A10 plays an important role in endothelial cell function by regulating plasmin production. In the absence of S100A10, endothelial cells fail to produce sufficient plasmin to maintain vascular patency and as a consequence fibrin clots accumulate in the tissues. S100A10 also regulates the movement of macrophages to the site of inflammation. S100A10 also plays a key role in oncogenesis by regulating the plasmin proteolytic activity of cancer cells and by regulating the migration of macrophages to the tumor site. The regulation of S100A10 levels by oncogenes such as PML-RAR $\alpha$ and oncogenic KRas presents the possibility that activation of the S100A10 gene may be of fundamental importance during the transformation process. Future studies are necessary to define exactly when during the cellular transformation process the S100A10 gene is activated and what are the functional consequences of that activation.

\section{Acknowledgments}

The authors were supported by a Grant from the Canadian Cancer Society Research Institute and Canadian Institutes of Health Research. The research by Dr. P. A. Madureira leading to these results has received funding from the European Union Seventh Framework Programme (FP7/2007-2013) under grant agreement no. PCOFUND-GA-2009-246542 and from the Foundation for Science and Technology of Portugal.

\section{References}

[1] J. D. Vassalli, A. P. Sappino, and D. Belin, "The plasminogen activator/plasmin system," Journal of Clinical Investigation, vol. 88, no. 4, pp. 1067-1072, 1991.
[2] E. F. Plow, J. Felez, and L. A. Miles, "Cellular regulation of fibrinolysis," Thrombosis and Haemostasis, vol. 66, no. 1, pp. 32-36, 1991.

[3] E. F. Plow and J. Hoover-Plow, "The functions of plasminogen in cardiovascular disease," Trends in Cardiovascular Medicine, vol. 14, no. 5, pp. 180-186, 2004.

[4] W. P. Fay, N. Garg, and M. Sunkar, "Vascular functions of the plasminogen activation system," Arteriosclerosis, Thrombosis, and Vascular Biology, vol. 27, no. 6, pp. 1231-1237, 2007.

[5] E. F. Plow, D. E. Freaney, J. Plescia, and L. A. Miles, "The plasminogen system and cell surfaces: evidence for plasminogen and urokinase receptors on the same cell type," Journal of Cell Biology, vol. 103, no. 6, pp. 2411-2420, 1986.

[6] V. Ellis, N. Behrendt, and K. Dano, "Plasminogen activation by receptor-bound urokinase: a kinetic study with both cell-associated and isolated receptor," Journal of Biological Chemistry, vol. 266, no. 19, pp. 12752-12758, 1991.

[7] L. A. Miles, C. M. Dahlberg, J. Plescia, J. Felez, K. Kato, and E. F. Plow, "Role of cell-surface lysines in plasminogen binding to cells: identification of $\alpha$-enolase as a candidate plasminogen receptor," Biochemistry, vol. 30, no. 6, pp. 16821691, 1991.

[8] J. Felez, C. J. Chanquia, P. Fabregas, E. F. Plow, and L. A. Miles, "Competition between plasminogen and tissue plasminogen activator for cellular binding sites," Blood, vol. 82, no. 8, pp. 2433-2441, 1993.

[9] J. Felez, "Plasminogen binding to cell surfaces," Fibrinolysis \& Proteolysis, vol. 12, no. 4, pp. 183-189, 1998.

[10] V. Ellis, "Plasminogen activation at the cell surface," Current Topics in Developmental Biology, vol. 54, pp. 263-312, 2003.

[11] H. M. Kang, K. S. Choi, G. Kassam, S. L. Fitzpatrick, M. Kwon, and D. M. Waisman, "Role of Annexin II tetramer in plasminogen activation," Trends in Cardiovascular Medicine, vol. 9, no. 3-4, pp. 92-102, 1999.

[12] M. Kwon, T. J. MacLeod, Y. Zhang, and D. M. Waisman, "S100A10, annexin A2, and annexin A2 heterotetramer as candidate plasminogen receptors," Frontiers in Bioscience, vol. 10, no. 1, pp. 300-325, 2005.

[13] D. K. Fogg, K. S. Choi, and D. M. Waisman, "Plasminogen receptors," in Plasminogen: Structure, Activation and Regulation, pp. 81-101, Kluwer Academic, New York, NY, USA, 2003.

[14] P. A. Madureira, A. P. Surette, K. D. Phipps, M. A. S. Taboski, V. A. Miller, and D. M. Waisman, "The role of the annexin A2 heterotetramer (AIIt) in vascular fibrinolysis," Blood, vol. 118, no. 18, pp. 4789-4797, 2011.

[15] G. Kassam, K. S. Choi, J. Ghuman et al., "The role of annexin II tetramer in the activation of plasminogen," Journal of Biological Chemistry, vol. 273, no. 8, pp. 4790-4799, 1998.

[16] M. Kwon and D. M. Waisman, "Mechanism of angiostatin formation from plasminogen," in Plasminogen: Structure, Activation, and Regulation, pp. 135-156, Kluwer academic, New York, NY, USA, 2003.

[17] T. Herren, C. Swaisgood, and E. F. Plow, "Regulation of plasminogen receptors," Frontiers in Bioscience, vol. 8, pp. D1-D8, 2003.

[18] L. A. Miles, S. B. Hawley, N. Baik, N. M. Andronicos, F. J. Castellino, and R. J. Parmer, "Plasminogen receptors: the sine qua non of cell surface plasminogen activation," Frontiers in Bioscience, vol. 10, no. 2, pp. 1754-1762, 2005.

[19] G. Kassam, B. H. Le, K. S. Choi et al., "The p11 subunit of the annexin II tetramer plays a key role in the stimulation of t-PA-dependent plasminogen activation," Biochemistry, vol. 37, no. 48, pp. 16958-16966, 1998. 
[20] D. K. Fogg, D. E. Bridges, K. K. T. Cheung et al., "The p11 subunit of annexin II heterotetramer is regulated by basic carboxypeptidase," Biochemistry, vol. 41, no. 15, pp. 49534961, 2002.

[21] U. Rescher and V. Gerke, "S100A10/p11: family, friends and functions," Pflugers Archiv European Journal of Physiology, vol. 455, no. 4, pp. 575-582, 2008.

[22] P. Svenningsson and P. Greengard, "p11 (S100A10)—an inducible adaptor protein that modulates neuronal functions," Current Opinion in Pharmacology, vol. 7, no. 1, pp. 27-32, 2007.

[23] E. A. Peterson, M. R. Sutherland, M. E. Nesheim, and E. L. G. Pryzdial, "Thrombin induces endothelial cell-surface exposure of the plasminogen receptor annexin 2," Journal of Cell Science, vol. 116, no. 12, pp. 2399-2408, 2003.

[24] B. Munz, V. Gerke, R. Gillitzer, and S. Werner, "Differential expression of the calpactin I subunits annexin II and p11 in cultured keratinocytes and during wound repair," Journal of Investigative Dermatology, vol. 108, no. 3, pp. 307-312, 1997.

[25] X. L. Huang, R. Pawliczak, M. J. Cowan et al., "Epidermal growth factor induces p11 gene and protein expression and down-regulates calcium ionophore-induced arachidonic acid release in human epithelial cells," Journal of Biological Chemistry, vol. 277, no. 41, pp. 38431-38440, 2002.

[26] S. Akiba, R. Hatazawa, K. Ono, M. Hayama, H. Matsui, and T. Sato, "Transforming growth factor- $\alpha$ stimulates prostaglandin generation through cytosolic phospholipase A2 under the control of p11 in rat gastric epithelial cells," British Journal of Pharmacology, vol. 131, no. 5, pp. 10041010, 2000.

[27] X. L. Huang, R. Pawliczak, X. L. Yao et al., "Interferon- $\gamma$ induces 11 gene and protein expression in human epithelial cells through interferon- $\gamma$-activated sequences in the p11 promoter," Journal of Biological Chemistry, vol. 278, no. 11, pp. 9298-9308, 2003.

[28] Y.-T. Fang, C.-F. Lin, C.-Y. Wang, R. Anderson, and Y.-S. Lin, "Interferon- $\gamma$ stimulates p11-dependent surface expression of annexin A2 in lung epithelial cells to enhance phagocytosis," Journal of Cellular Physiology, vol. 227, no. 6, pp. 27752787, 2012.

[29] P. A. O’Connell, P. A. Madureira, J. N. Berman, R. S. Liwski, and D. M. Waisman, "Regulation of S100A10 by the PMLRAR- $\alpha$ oncoprotein,” Blood, vol. 117, no. 15, pp. 4095-4105, 2011.

[30] D. Cavallo-Medved, J. Dosescu, B. E. Linebaugh, M. Sameni, D. Rudy, and B. F. Sloane, "Mutant K-ras regulates cathepsin B localization on the surface of human colorectal carcinoma cells," Neoplasia, vol. 5, no. 6, pp. 507-519, 2003.

[31] E. Erikson, H. G. Tomasiewicz, and R. L. Erikson, "Biochemical characterization of a 34-kilodalton normal cellular substrate of pp60v-src and an associated 6-kilodalton protein," Molecular and Cellular Biology, vol. 4, no. 1, pp. 77-85, 1984.

[32] V. Gerke and K. Weber, "The regulatory chain in the p36-kd substrate complex of viral tyrosine-specific protein kinases is related in sequence to the S-100 protein of glial cells," The EMBO Journal, vol. 4, no. 11, pp. 2917-2920, 1985.

[33] J. R. Glenney and B. F. Tack, "Amino-terminal sequence of p36 and associated p10: identification of the site of tyrosine phosphorylation and homology with S-100," Proceedings of the National Academy of Sciences of the United States of America, vol. 82, no. 23, pp. 7884-7888, 1985.

[34] N. Johnsson, J. Vandekerckhove, J. van Damme, and K. Weber, "Binding sites for calcium, lipid and p11 on p36, the substrate of retroviral tyrosine-specific protein kinases," FEBS Letters, vol. 198, no. 2, pp. 361-365, 1986.

[35] M. Hagiwara, M. Ochiai, K. Owada, T. Tanaka, and H. Hidaka, "Modulation of tyrosine phosphorylation of p36 and other substrates by the S-100 protein," Journal of Biological Chemistry, vol. 263, no. 13, pp. 6438-6441, 1988.

[36] C. Thiel, M. Osborn, and V. Gerke, "The tight association of the tyrosine kinase substrate annexin II with the submembranous cytoskeleton depends on intact p11- and Ca2 ${ }^{+}$-binding sites," Journal of Cell Science, vol. 103, no. 3, pp. 733-742, 1992.

[37] L. Zokas and J. R. Glenney, "The calpactin light chain is tightly linked to the cytoskeletal form of calpactin I: studies using monoclonal antibodies to calpactin subunits," Journal of Cell Biology, vol. 105, no. 5, pp. 2111-2121, 1987.

[38] D. S. Drust and C. E. Creutz, "Aggregation of chromafin granules by calpactin at micromolar levels of calcium," Nature, vol. 331, no. 6151, pp. 88-91, 1988.

[39] D. M. Waisman, "Annexin II tetramer: structure and function," Molecular and Cellular Biochemistry, vol. 149-150, pp. 301-322, 1995.

[40] M. Garbuglia, R. Bianchi, M. Verzini, I. Giambanco, and R. Donato, "Annexin II2-p112 (calpactin I) stimulates the assembly of GFAP in a calcium- and pH-dependent manner," Biochemical and Biophysical Research Communications, vol. 208, no. 3, pp. 901-909, 1995.

[41] C. M. Raynor, J. F. Wright, D. M. Waisman, and E. L. G. Pryzdial, "Annexin II enhances cytomegalovirus binding and fusion to phospholipid membranes," Biochemistry, vol. 38, no. 16, pp. 5089-5095, 1999.

[42] J. F. Wright, A. Kurosky, E. L. G. Pryzdial, and S. Wasi, "Host cellular annexin II is associated with cytomegalovirus particles isolated from cultured human fibroblasts," Journal of Virology, vol. 69, no. 8, pp. 4784-4791, 1995.

[43] T. Wu, C. W. Angus, X. L. Yao, C. Logun, and J. H. Shelhamer, "p11, a unique member of the S100 family of calciumbinding proteins, interacts with and inhibits the activity of the 85-kDa cytosolic phospholipase A2," Journal of Biological Chemistry, vol. 272, no. 27, pp. 17145-17153, 1997.

[44] S. Y. Hsu, A. Kaipia, L. Zhu, and A. J. W. Hsueh, "Interference of BAD (Bcl-xL/Bcl-2-associated death promoter)-induced apoptosis in mammalian cells by 14-3-3 isoforms and P11," Molecular Endocrinology, vol. 11, no. 12, pp. 1858-1867, 1997.

[45] F. Le Bouffant, J. Capdevielle, J. C. Guillemot, and F. Sladeczek, "Characterization of brain PCTAIRE-1 kinase immunoreactivity and its interactions with p11 and 14-3-3 proteins," European Journal of Biochemistry, vol. 257, no. 1, pp. 112-120, 1998.

[46] F. Sladeczek, J. H. Camonis, A. F. Burnol, and F. Le Bouffant, "The Cdk-like protein PCTAIRE-1 from mouse brain associates with $\mathrm{p} 11$ and 14-3-3 proteins," Molecular and General Genetics, vol. 254, no. 5, pp. 571-577, 1997.

[47] M. Ruse, A. Lambert, N. Robinson, D. Ryan, K. J. Shon, and R. L. Eckert, "S100A7, S100A10, and S100A11 are transglutaminase substrates," Biochemistry, vol. 40, no. 10, pp. 3167-3173, 2001.

[48] A. R. Beaton, J. Rodriguez, Y. K. Reddy, and P. Roy, “The membrane trafficking protein calpactin forms a complex with bluetongue virus protein $\mathrm{NS}_{3}$ and mediates virus release," Proceedings of the National Academy of Sciences of the United States of America, vol. 99, no. 20, pp. 13154-13159, 2002. 
[49] J. Choi, J. S. Chang, M. S. Song et al., "Association of hepatitis $B$ virus polymerase with promyelocytic leukemia nuclear bodies mediated by the $\mathrm{S} 100$ family protein $\mathrm{p} 11$," Biochemical and Biophysical Research Communications, vol. 305, no. 4, pp. 1049-1056, 2003.

[50] C. Benaud, B. J. Gentil, N. Assard et al., "AHNAK interaction with the annexin 2/S100A10 complex regulates cell membrane cytoarchitecture," Journal of Cell Biology, vol. 164, no. 1, pp. 133-144, 2004.

[51] C. Girard, N. Tinel, C. Terrenoire, G. Romey, M. Lazdunski, and M. Borsotto, "p11, an annexin II subunit, an auxiliary protein associated with the background $\mathrm{K}^{+}$channel, TASK1," The EMBO Journal, vol. 21, no. 17, pp. 4439-4448, 2002.

[52] S. F. J. van de Graaf, J. G. J. Hoenderop, D. Gkika et al., "Functional expression of the epithelial $\mathrm{Ca}^{2+}$ channels (TRPV5 and TRPV6) requires association of the S100A10annexin 2 complex," The EMBO Journal, vol. 22, no. 7, pp. 1478-1487, 2003.

[53] E. Donier, F. Rugiero, K. Okuse, and J. N. Wood, "Annexin II light chain p11 promotes functional expression of acidsensing ion channel ASIC1a," Journal of Biological Chemistry, vol. 280, no. 46, pp. 38666-38672, 2005.

[54] K. Okuse, M. Malik-Hall, M. D. Baker et al., "Annexin II light chain regulates sensory neuron-specific sodium channel expression," Nature, vol. 417, no. 6889, pp. 653-656, 2002.

[55] W. Y. L. Poon, M. Malik-Hall, J. N. Wood, and K. Okuse, "Identification of binding domains in the sodium channel NaV1.8 intracellular N-terminal region and annexin II light chain p11," FEBS Letters, vol. 558, no. 1-3, pp. 114-118, 2004.

[56] P. Svenningsson, K. Chergui, I. Rachleff et al., "Alterations in 5-HT1B receptor function by p11 in depression-like states," Science, vol. 311, no. 5757, pp. 77-80, 2006.

[57] T. Foulkes, M. A. Nassar, T. Lane et al., "Deletion of annexin 2 light chain p11 in nociceptors causes deficits in somatosensory coding and pain behavior," Journal of Neuroscience, vol. 26, no. 41, pp. 10499-10507, 2006.

[58] K. S. Choi, J. Ghuman, G. Kassam, H. M. Kang, S. L. Fitzpatrick, and D. M. Waisman, "Annexin II tetramer inhibits plasmin-dependent fibrinolysis," Biochemistry, vol. 37, no. 2, pp. 648-655, 1998.

[59] K. S. Choi, D. K. Fogg, S. L. Fitzpatrick, and D. M. Waisman, "Role of annexin II tetramer in the regulation of plasmin activity," in Annexins: Biological Importance and AnnexinRelated Pathologies, pp. 218-233, Landes Bioscience, Austin, Tex, USA, 2003.

[60] G. Kassam, M. Kwon, C. S. Yoon et al., "Purification and characterization of A61: an angiostatin-like plasminogen fragment produced by plasmin autodigestion in the absence of sulfhydryl donors," Journal of Biological Chemistry, vol. 276, no. 12, pp. 8924-8933, 2001.

[61] M. Kwon, C. S. Yoon, S. Fitzpatrick et al., "p22 is a novel plasminogen fragment with antiangiogenic activity," Biochemistry, vol. 40, no. 44, pp. 13246-13253, 2001.

[62] H. M. Kang, G. Kassam, S. E. Jarvis, S. L. Fitzpatrick, and D. M. Waisman, "Characterization of human recombinant annexin II tetramer purified from bacteria: role of $\mathrm{N}$ terminal acetylation," Biochemistry, vol. 36, no. 8, pp. 20412050, 1997.

[63] T. J. MacLeod, M. Kwon, N. R. Filipenko, and D. M. Waisman, "Phospholipid-associated annexin A2-S100A10 heterotetramer and its subunits. Characterization of the interaction with tissue plasminogen activator, plasminogen, and plasmin," Journal of Biological Chemistry, vol. 278, no. 28, pp. 25577-25584, 2003.
[64] K. S. Choi, D. K. Fogg, C. S. Yoon, and D. M. Waisman, "p11 regulates extracellular plasmin production and invasiveness of HT1080 fibrosarcoma cells," The FASEB Journal, vol. 17, no. 2, pp. 235-246, 2003.

[65] L. Zhang, D. K. Fogg, and D. M. Waisman, "RNA interference-mediated silencing of the S100A10 gene attenuates plasmin generation and invasiveness of colo 222 colorectal cancer cells," Journal of Biological Chemistry, vol. 279, no. 3, pp. 2053-2062, 2004.

[66] A. P. Surette, P. A. Madureira, K. D. Phipps, V. A. Miller, P. Svenningsson, and D. M. Waisman, "Regulation of fibrinolysis by S100A10 in vivo," Blood, vol. 118, no. 11, pp. 31723181, 2011.

[67] P. A. O’Connell, A. P. Surette, R. S. Liwski, P. Svenningsson, and D. M. Waisman, "S100A10 regulates plasminogendependent macrophage invasion," Blood, vol. 116, no. 7, pp. 1136-1146, 2010.

[68] K. D. Phipps, A. P. Surette, P. A. O'Connell, and D. M. Waisman, "Plasminogen receptor S100A10 is essential for the migration of tumor-promoting macrophages into tumor sites," Cancer Research, vol. 71, pp. 6676-6683, 2011.

[69] X. Yang, N. C. Popescu, and D. B. Zimonjic, "DLC1 interaction with S100A10 mediates inhibition of in vitro cell invasion and tumorigenicity of lung cancer cells through a rhogap-independent mechanism," Cancer Research, vol. 71, no. 8, pp. 2916-2925, 2011.

[70] R. Donato, "S100: a multigenic family of calcium-modulated proteins of the EF-hand type with intracellular and extracellular functional roles," International Journal of Biochemistry and Cell Biology, vol. 33, no. 7, pp. 637-668, 2001.

[71] A. C. Rintala-Dempsey, A. Rezvanpour, and G. S. Shaw, "S100-annexin complexes-structural insights," The FEBS Journal, vol. 275, no. 20, pp. 4956-4966, 2008.

[72] L. Santamaria-Kisiel, A. C. Rintala-Dempsey, and G. S. Shaw, "Calcium-dependent and -independent interactions of the S100 protein family," Biochemical Journal, vol. 396, no. 2, pp. 201-214, 2006.

[73] T. Ravasi, K. Hsu, J. Goyette et al., "Probing the S100 protein family through genomic and functional analysis," Genomics, vol. 84, no. 1, pp. 10-22, 2004.

[74] R. H. Kretsinger and C. E. Nockolds, "Carp muscle calciumbinding protein. II. Structure determination and general description," Journal of Biological Chemistry, vol. 248, no. 9, pp. 3313-3326, 1973.

[75] M. C. Schaub and C. W. Heizmann, "Calcium, troponin, calmodulin, S100 proteins: from myocardial basics to new therapeutic strategies," Biochemical and Biophysical Research Communications, vol. 369, no. 1, pp. 247-264, 2008.

[76] O. V. Moroz, K. S. Wilson, and I. B. Bronstein, "The role of zinc in the $\mathrm{S} 100$ proteins: insights from the X-ray structures," Amino Acids, vol. 41, no. 4, pp. 761-772, 2010.

[77] I. Marenholz, C. W. Heizmann, and G. Fritz, "S100 proteins in mouse and man: from evolution to function and pathology (including an update of the nomenclature)," Biochemical and Biophysical Research Communications, vol. 322, no. 4, pp. 1111-1122, 2004.

[78] D. Waisman, F. C. Stevens, and J. H. Wang, "The distribution of the $\mathrm{Ca}^{++}$dependent protein activator of cyclic nucleotide phosphodiesterase in invertebrates," Biochemical and Biophysical Research Communications, vol. 65, no. 3, pp. 975982, 1975.

[79] Y. Zhou, W. Yang, M. Kirberger, H. W. Lee, G. Ayalasomayajula, and J. J. Yang, "Prediction of EF-hand calcium-binding 
proteins and analysis of bacterial EF-hand proteins," Proteins, vol. 65, no. 3, pp. 643-655, 2006.

[80] K. Kizawa, H. Takahara, M. Unno, and C. W. Heizmann, "S100 and S100 fused-type protein families in epidermal maturation with special focus on S100A3 in mammalian hair cuticles," Biochimie, vol. 93, no. 12, pp. 2038-2047, 2011.

[81] E. Lukanidin and J. P. Sleeman, "Building the niche: the role of the S100 proteins in metastatic growth," Seminars in Cancer Biology, vol. 22, no. 3, pp. 216-225, 2012.

[82] S. E. Permyakov, R. G. Ismailov, B. Xue, A. I. Denesyuk, V. N. Uversky, and E. A. Permyakov, "Intrinsic disorder in S100 proteins," Molecular BioSystems, vol. 7, no. 7, pp. 2164-2180, 2011.

[83] I. P. Korndörfer, F. Brueckner, and A. Skerra, "The crystal structure of the human (S100A8/S100A9)2 heterotetramer, calprotectin, illustrates how conformational changes of interacting $\alpha$-helices can determine specific association of two EFhand proteins," Journal of Molecular Biology, vol. 370, no. 5, pp. 887-898, 2007.

[84] F. L. Imai, K. Nagata, N. Yonezawa, M. Nakano, and M. Tanokura, "Structure of calcium-bound human S100A13 at pH 7.5 at $1.8 \AA$ resolution," Acta Crystallographica Section F, vol. 64, no. 2, pp. 70-76, 2008.

[85] S. Réty, J. Sopkova, M. Renouard et al., "The crystal structure of a complex of p11 with the annexin II N-terminal peptide," Nature Structural Biology, vol. 6, no. 1, pp. 89-95, 1999.

[86] N. Johnsson, G. Marriott, and K. Weber, "p36, the major cytoplasmic substrate of src tyrosine protein kinase, binds to its p11 regulatory subunit via a short amino-terminal amphiphatic helix," The EMBO Journal, vol. 7, no. 8, pp. 2435-2442, 1988.

[87] T. Becker, K. Weber, and N. Johnsson, "Protein-protein recognition via short amphiphilic helices; a mutational analysis of the binding site of annexin II for p11," The EMBO Journal, vol. 9, no. 13, pp. 4207-4213, 1990.

[88] E. Kube, T. Becker, K. Weber, and V. Gerke, "Proteinprotein interaction studied by site-directed mutagenesis. Characterization of the annexin II-binding site on p11, a member of the S100 protein family," Journal of Biological Chemistry, vol. 267, no. 20, pp. 14175-14182, 1992.

[89] L. A. Borthwick, A. Neal, L. Hobson, V. Gerke, L. Robson, and R. Muimo, "The annexin 2-S100A10 complex and its association with TRPV6 is regulated by cAMP/PKA/CnA in airway and gut epithelia," Cell Calcium, vol. 44, no. 2, pp. 147-157, 2008.

[90] J. Mai, R. L. Finley, D. M. Waisman, and B. F. Sloane, "Human procathepsin B interacts with the annexin II tetramer on the surface of tumor cells," Journal of Biological Chemistry, vol. 275, no. 17, pp. 12806-12812, 2000.

[91] J. Mai, D. M. Waisman, and B. F. Sloane, "Cell surface complex of cathepsin B/annexin II tetramer in malignant progression," Biochimica et Biophysica Acta, vol. 1477, no. 12, pp. 215-230, 2000.

[92] S. de Seranno, C. Benaud, N. Assard et al., "Identification of an AHNAK binding motif specific for the Annexin2/S100A10 tetramer," Journal of Biological Chemistry, vol. 281, no. 46, pp. 35030-35038, 2006.

[93] A. Rezvanpour and G. S. Shaw, "Unique S100 target protein interactions," General Physiology and Biophysics, vol. 28, pp. F39-F46, 2009.

[94] E. F. Plow, T. Herren, A. Redlitz, L. A. Miles, and J. L. HooverPlow, "The cell biology of the plasminogen system," The FASEB Journal, vol. 9, no. 10, pp. 939-945, 1995.
[95] A. Semov, M. J. Moreno, A. Onichtchenko et al., "Metastasisassociated protein S100A4 induces angiogenesis through interaction with annexin II and accelerated plasmin formation," Journal of Biological Chemistry, vol. 280, no. 21, pp. 20833-20841, 2005.

[96] M. T. Christen, P. Frank, J. Schaller, and M. Llinás, "Human plasminogen kringle 3: solution structure, functional insights, phylogenetic landscape," Biochemistry, vol. 49, no. 33, pp. 7131-7150, 2010.

[97] X. Shang, J. Sun, Y. He et al., "Identification and predominant expression of annexin A2 in epithelial-type cells of the rice field eel," Journal of Cellular Biochemistry, vol. 101, no. 3, pp. 600-608, 2007.

[98] T. Harder, E. Kube, and V. Gerke, "Cloning and characterization of the human gene encoding p11: structural similarity to other members of the S-100 gene family," Gene, vol. 113, no. 2, pp. 269-274, 1992.

[99] L. Zhang, H. Li, T. P. Su et al., "p11 is up-regulated in the forebrain of stressed rats by glucocorticoid acting via two specific glucocorticoid response elements in the p11 promoter," Neuroscience, vol. 153, no. 4, pp. 1126-1134, 2008.

[100] L. Zhang, H. Li, X. Hu, X. X. Li, S. Smerin, and R. Ursano, "Glucocorticoid-induced p11 over-expression and chromatin remodeling: a novel molecular mechanism of traumatic stress?" Medical Hypotheses, vol. 76, no. 6, pp. 774777, 2011.

[101] X. L. Yao, M. J. Cowan, M. T. Gladwin, M. M. Lawrence, C. W. Angus, and J. H. Shelhamer, "Dexamethasone alters arachidonate release from human epithelial cells by induction of 11 protein synthesis and inhibition of phospholipase A2 activity," Journal of Biological Chemistry, vol. 274, no. 24, pp. 17202-17208, 1999.

[102] S. Y. Chun, H. W. Bae, W. J. Kim, J. H. Park, S. Y. Hsu, and A. J. W. Hsueh, "Expression of messenger ribonucleic acid for the antiapoptosis gene P11 in the rat ovary: gonadotropin stimulation in granulosa cells of preovulatory follicles," Endocrinology, vol. 142, no. 6, pp. 2311-2317, 2001.

[103] P. A. Melas, M. Rogdaki, A. Lennartsson et al., "Antidepressant treatment is associated with epigenetic alterations in the promoter of P11 in a genetic model of depression," International Journal of Neuropsychopharmacology, vol. 15, no. 5, pp. 669-679, 2012.

[104] A. Puisieux, J. Ji, and M. Ozturk, "Annexin II up-regulates cellular levels of p11 protein by a post-translational mechanism," Biochemical Journal, vol. 313, part 1, pp. 51-55, 1996.

[105] M. T. Gladwin, X. L. Yao, M. Cowan et al., "Retinoic acid reduces p11 protein levels in bronchial epithelial cells by a posttranslational mechanism," American Journal of Physiology_Lung Cellular and Molecular Physiology, vol. 279, no. 6, pp. L1103-L1109, 2000.

[106] J. Zhang, B. Guo, Y. Zhang, J. Cao, and T. Chen, "Silencing of the annexin II gene down-regulates the levels of S100A10, cMyc, and plasmin and inhibits breast cancer cell proliferation and invasion," Saudi Medical Journal, vol. 31, no. 4, pp. 374381, 2010.

[107] Y. Hou, L. Yang, M. Mou et al., "Annexin A2 regulates the levels of plasmin, S100A10 and fascin in L5178Y cells," Cancer Investigation, vol. 26, no. 8, pp. 809-815, 2008.

[108] J. Glenney, "Phospholipid-dependent $\mathrm{Ca}^{+}$binding by the $36-\mathrm{kDa}$ tyrosine kinase substrate (calpactin) and its $33-\mathrm{kDa}$ core," Journal of Biological Chemistry, vol. 261, no. 16, pp. 7247-7252, 1986. 
[109] E. B. Babiychuk and A. Draeger, "Annexins in cell membrane dynamics: $\mathrm{Ca}_{2}^{+}$-regulated association of lipid microdomains," Journal of Cell Biology, vol. 150, no. 5, pp. 1113-1123, 2000.

[110] N. R. Filipenko, H. M. Kang, and D. M. Waisman, "Characterization of the $\mathrm{Ca}_{2}{ }^{+}$-binding sites of annexin II tetramer," Journal of Biological Chemistry, vol. 276, pp. 38877-38884, 2001.

[111] A. B. Deora, G. Kreitzer, A. T. Jacovina, and K. A. Hajjar, “An annexin 2 phosphorylation switch mediates p11-dependent translocation of annexin 2 to the cell surface," Journal of Biological Chemistry, vol. 279, no. 42, pp. 43411-43418, 2004.

[112] L. Zheng, K. Foley, L. Huang et al., "Tyrosine 23 phosphorylation-dependent cell-surface localization of annexin A2 is required for invasion and metastases of pancreatic cancer," PLoS One, vol. 6, no. 4, Article ID e19390, 2011.

[113] M. Valapala and J. K. Vishwanatha, "Lipid raft endocytosis and exosomal transport facilitate extracellular trafficking of annexin A2," Journal of Biological Chemistry, vol. 286, no. 35, pp. 30911-30925, 2011.

[114] W. Nickel, "Pathways of unconventional protein secretion," Current Opinion in Biotechnology, vol. 21, no. 5, pp. 621-626, 2010.

[115] V. Renigunta, H. Yuan, M. Zuzarte et al., "The retention factor p11 confers an endoplasmic reticulum-localization signal to the potassium channel TASK-1," Traffic, vol. 7, no. 2, pp. 168-181, 2006.

[116] J. F. A. Swisher, N. Burton, S. M. Bacot, S. N. Vogel, and G. M. Feldman, "Annexin A2 tetramer activates human and murine macrophages through TLR4," Blood, vol. 115, no. 3, pp. 549$558,2010$.

[117] T. Syrovets, B. Tippler, M. Rieks, and T. Simmet, "Plasmin is a potent and specific chemoattractant for human peripheral monocytes acting via a cyclic guanosine monophosphatedependent pathway," Blood, vol. 89, no. 12, pp. 4574-4583, 1997.

[118] R. Rust, L. Visser, J. van der Leij et al., "High expression of calcium-binding proteins, S100A10, S100A11 and CALM2 in anaplastic large cell lymphoma," British Journal of Haematology, vol. 131, no. 5, pp. 596-608, 2005.

[119] T. Domoto, Y. Miyama, H. Suzuki et al., "Evaluation of S100A10, annexin II and B-FABP expression as markers for renal cell carcinoma," Cancer Science, vol. 98, no. 1, pp. 7782, 2007.

[120] J. Li, A. K. Riau, M. Setiawan et al., "S100A expression in normal corneal-limbal epithelial cells and ocular surface squamous cell carcinoma tissue," Molecular Vision, vol. 17, pp. 2263-2271, 2011.

[121] S. Suzuki, Y. Yamayoshi, A. Nishimuta, and Y. Tanigawara, "S100A10 protein expression is associated with oxaliplatin sensitivity in human colorectal cancer cells," Proteome Science, vol. 9, Article ID 76, 2011.

[122] C. J. Saris, T. Kristensen, P. D’Eustachio et al., “cDNA sequence and tissue distribution of the mRNA for bovine and murine $\mathrm{p} 11$, the S100-related light chain of the proteintyrosine kinase substrate p36 (calpactin I)," Journal of Biological Chemistry, vol. 262, no. 22, pp. 10663-10671, 1987.

[123] E. Venetsanakos, A. Mirza, C. Fanton, S. R. Romanov, T. Tlsty, and M. McMahon, "Induction of tubulogenesis in telomerase-immortalized human microvascular endothelial cells by glioblastoma cells," Experimental Cell Research, vol. 273, no. 1, pp. 21-33, 2002.

[124] Y. Laumonnier, T. Syrovets, L. Burysek, and T. Simmet, "Identification of the annexin A2 heterotetramer as a receptor for the plasmin-induced signaling in human peripheral monocytes," Blood, vol. 107, no. 8, pp. 3342-3349, 2006.

[125] Q. Li, Y. Laumonnier, T. Syrovets, and T. Simmet, "Plasmin triggers cytokine induction in human monocyte-derived macrophages," Arteriosclerosis, Thrombosis, and Vascular Biology, vol. 27, no. 6, pp. 1383-1389, 2007.

[126] P. Manivet, B. Schneider, J. C. Smith et al., "The serotonin binding site of human and murine 5-HT2B receptors. Molecular modeling and site-directed mutagenesis," Journal of Biological Chemistry, vol. 277, no. 19, pp. 17170-17178, 2002.

[127] C. Moret and M. Briley, "The possible role of 5-HT(1B/D) receptors in psychiatric disorders and their potential as a target for therapy," European Journal of Pharmacology, vol. 404, no. 1-2, pp. 1-12, 2000.

[128] J. A. Gingrich and R. Hen, "Dissecting the role of the serotonin system in neuropsychiatric disorders using knockout mice," Psychopharmacology, vol. 155, no. 1, pp. 1-10, 2001.

[129] F. Saudou and R. Hen, "5-Hydroxytryptamine receptor subtypes: molecular and functional diversity," Advances in Pharmacology, vol. 30, pp. 327-380, 1994.

[130] J. L. Warner-Schmidt, M. Flajolet, A. Maller et al., "Role of p11 in cellular and behavioral effects of 5-HT4 receptor stimulation," Journal of Neuroscience, vol. 29, no. 6, pp. 19371946, 2009.

[131] Y. Gong, E. Hart, A. Shchurin, and J. Hoover-Plow, "Inflammatory macrophage migration requires MMP-9 activation by plasminogen in mice," Journal of Clinical Investigation, vol. 118, no. 9, pp. 3012-3024, 2008.

[132] M. Wygrecka, L. M. Marsh, R. E. Morty et al., "Enolase-1 promotes plasminogen-mediated recruitment of monocytes to the acutely inflamed lung," Blood, vol. 113, no. 22, pp. 5588-5598, 2009.

[133] R. Das, T. Burke, and E. F. Plow, "Histone H2B as a functionally important plasminogen receptor on macrophages," Blood, vol. 110, no. 10, pp. 3763-3772, 2007.

[134] S. Lighvani, N. Baik, J. E. Diggs, S. Khaldoyanidi, R. J. Parmer, and L. A. Miles, "Regulation of macrophage migration by a novel plasminogen receptor Plg $-\mathrm{R}_{\mathrm{KT}}$," Blood, vol. 118, no. 20, pp. 5622-5630, 2011.

[135] V. A. Ploplis, E. L. French, P. Carmeliet, D. Collen, and E. F. Plow, "Plasminogen deficiency differentially affects recruitment of inflammatory cell populations in mice," Blood, vol. 91, no. 6, pp. 2005-2009, 1998.

[136] C. Brownstein, A. B. Deora, A. T. Jacovina et al., "Annexin II mediates plasminogen-dependent matrix invasion by human monocytes: enhanced expression by macrophages," Blood, vol. 103, no. 1, pp. 317-324, 2004.

[137] D. J. Falcone, W. Borth, K. M. F. Khan, and K. A. Hajjar, "Plasminogen-mediated matrix invasion and degradation by macrophages is dependent on surface expression of annexin II," Blood, vol. 97, no. 3, pp. 777-784, 2001.

[138] G. M. Cesarman, C. A. Guevara, and K. A. Hajjar, "An endothelial cell receptor for plasminogen/tissue plasminogen activator (t-PA). II. Annexin II-mediated enhancement of tPA-dependent plasminogen activation," Journal of Biological Chemistry, vol. 269, no. 33, pp. 21198-21203, 1994. 
[139] K. A. Hajjar, A. T. Jacovina, and J. Chacko, "An endothelial cell receptor for plasminogen/tissue plasminogen activator. I. Identity with annexin II," Journal of Biological Chemistry, vol. 269, no. 33, pp. 21191-21197, 1994.

[140] K. L. He, A. B. Deora, H. Xiong et al., "Endothelial cell annexin A2 regulates polyubiquitination and degradation of its binding partner S100A10/p11," Journal of Biological Chemistry, vol. 283, no. 28, pp. 19192-19200, 2008.

[141] S. U. Lauvrak, H. Hollås, A. P. Døskeland, I. Aukrust, T. Flatmark, and A. Vedeler, "Ubiquitinated annexin A2 is enriched in the cytoskeleton fraction," FEBS Letters, vol. 579, no. 1, pp. 203-206, 2005.

[142] U. Rescher, C. Ludwig, V. Konietzko, A. Kharitonenkov, and V. Gerke, "Tyrosine phosphorylation of annexin A2 regulates Rho-mediated actin rearrangement and cell adhesion," Journal of Cell Science, vol. 121, no. 13, pp. 2177-2185, 2008.

[143] H. C. Kwaan, "The plasminogen-plasmin system in malignancy," Cancer and Metastasis Reviews, vol. 11, no. 3-4, pp. 291-311, 1992.

[144] M. Del Rosso, G. Fibbi, M. Pucci et al., "Multiple pathways of cell invasion are regulated by multiple families of serine proteases," Clinical and Experimental Metastasis, vol. 19, no. 3, pp. 193-207, 2002.

[145] H. W. Smith and C. J. Marshall, "Regulation of cell signalling by uPAR," Nature Reviews Molecular Cell Biology, vol. 11, no. 1, pp. 23-36, 2010.

[146] F. Blasi and N. Sidenius, "The urokinase receptor: focused cell surface proteolysis, cell adhesion and signaling," FEBS Letters, vol. 584, no. 9, pp. 1923-1930, 2010.

[147] K. S. Siveen and G. Kuttan, "Role of macrophages in tumour progression," Immunology Letters, vol. 123, no. 2, pp. 97-102, 2009.

[148] J. Wyckoff, W. Wang, E. Y. Lin et al., "A paracrine loop between tumor cells and macrophages is required for tumor cell migration in mammary tumors," Cancer Research, vol. 64, no. 19, pp. 7022-7029, 2004.

[149] J. Condeelis and J. W. Pollard, "Macrophages: obligate partners for tumor cell migration, invasion, and metastasis," Cell, vol. 124, no. 2, pp. 263-266, 2006.

[150] L. Degos, "The history of acute promyelocytic leukaemia," British Journal of Haematology, vol. 122, no. 4, pp. 539-553, 2003.

[151] M. S. Tallman, "The thrombophilic state in acute promyelocytic leukemia," Seminars in Thrombosis and Hemostasis, vol. 25, no. 2, pp. 209-215, 1999.

[152] T. Barbui and A. Falanga, "Disseminated intravascular coagulation in acute leukemia," Seminars in Thrombosis and Hemostasis, vol. 27, no. 6, pp. 593-604, 2001.

[153] H. C. Kwaan, J. Wang, and L. N. Boggio, "Abnormalities in hemostasis in acute promyelocytic leukemia," Hematological Oncology, vol. 20, no. 1, pp. 33-41, 2002.

[154] J. S. Menell, G. M. Cesarman, A. T. Jacovina, M. A. McLaughlin, E. A. Lev, and K. A. Hajjar, "Annexin II and bleeding in acute promyelocytic leukemia," New England Journal of Medicine, vol. 340, no. 13, pp. 994-1004, 1999.

[155] S. A. Olwill, H. McGlynn, W. S. Gilmore, and H. D. Alexander, "All-trans retinoic acid-induced downregulation of annexin II expression in myeloid leukaemia cell lines is not confined to acute promyelocytic leukaemia," British Journal of Haematology, vol. 131, no. 2, pp. 258-264, 2005.
[156] K. H. Lee, M. Y. Chang, J. I. Ahn et al., "Differential gene expression in retinoic acid-induced differentiation of acute promyelocytic leukemia cells, NB4 and HL-60 cells," Biochemical and Biophysical Research Communications, vol. 296, no. 5, pp. 1125-1133, 2002.

[157] D. Cavallo-Medved, J. Dosescu, B. E. Linebaugh, M. Sameni, D. Rudy, and B. F. Sloane, "Mutant K-ras regulates cathepsin B localization on the surface of human colorectal carcinoma cells," Neoplasia, vol. 5, no. 6, pp. 507-519, 2003. 

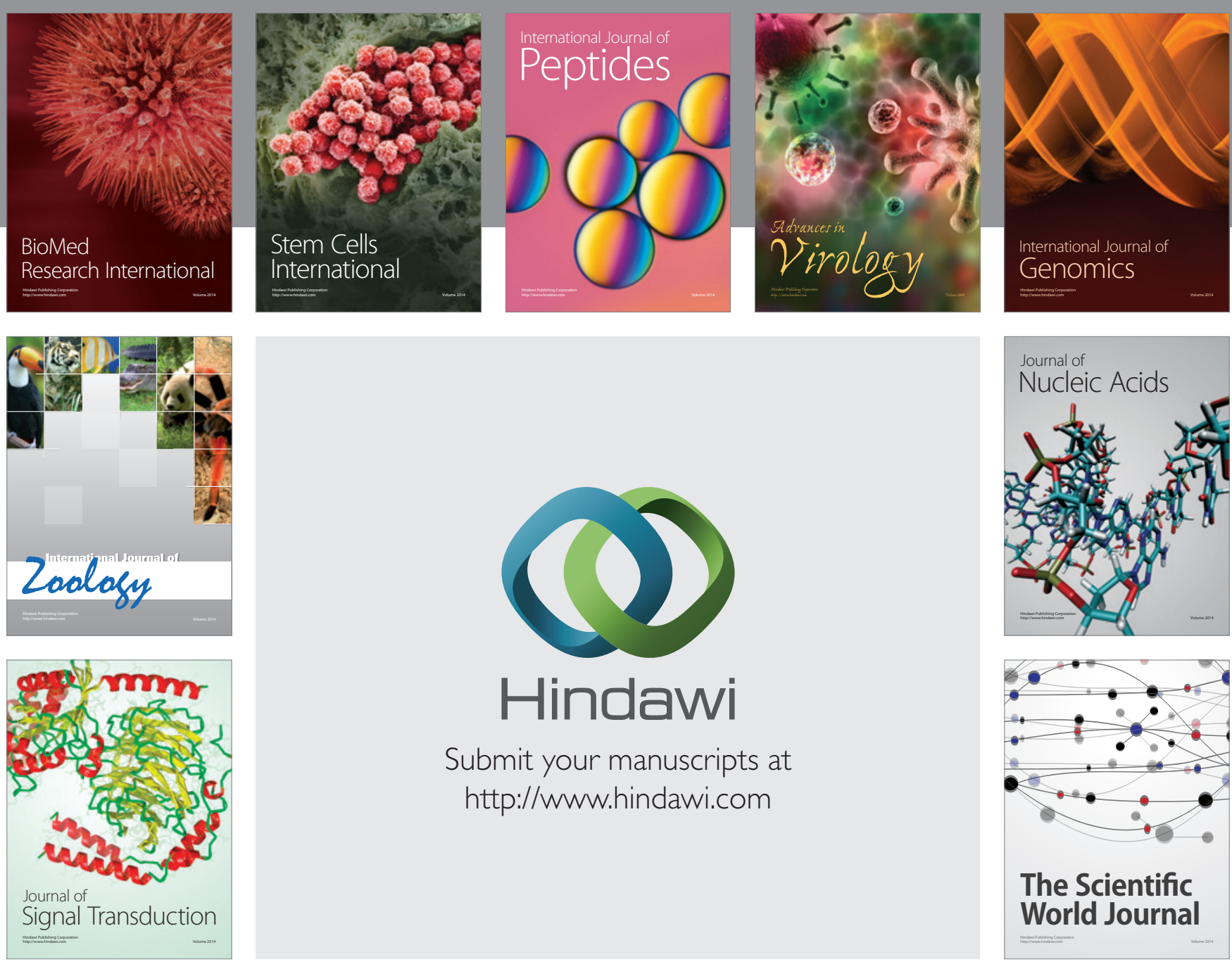

Submit your manuscripts at

http://www.hindawi.com
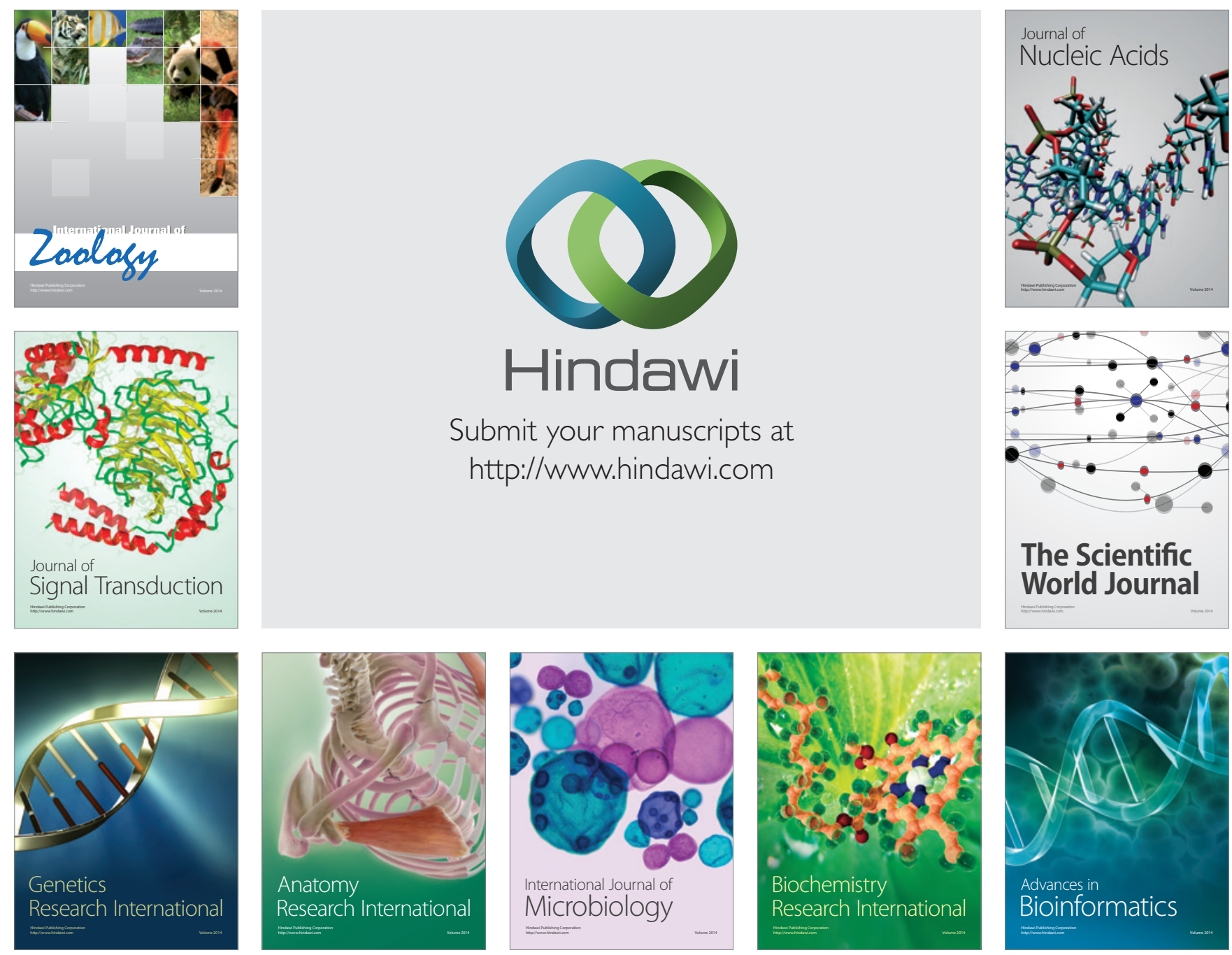

The Scientific World Journal
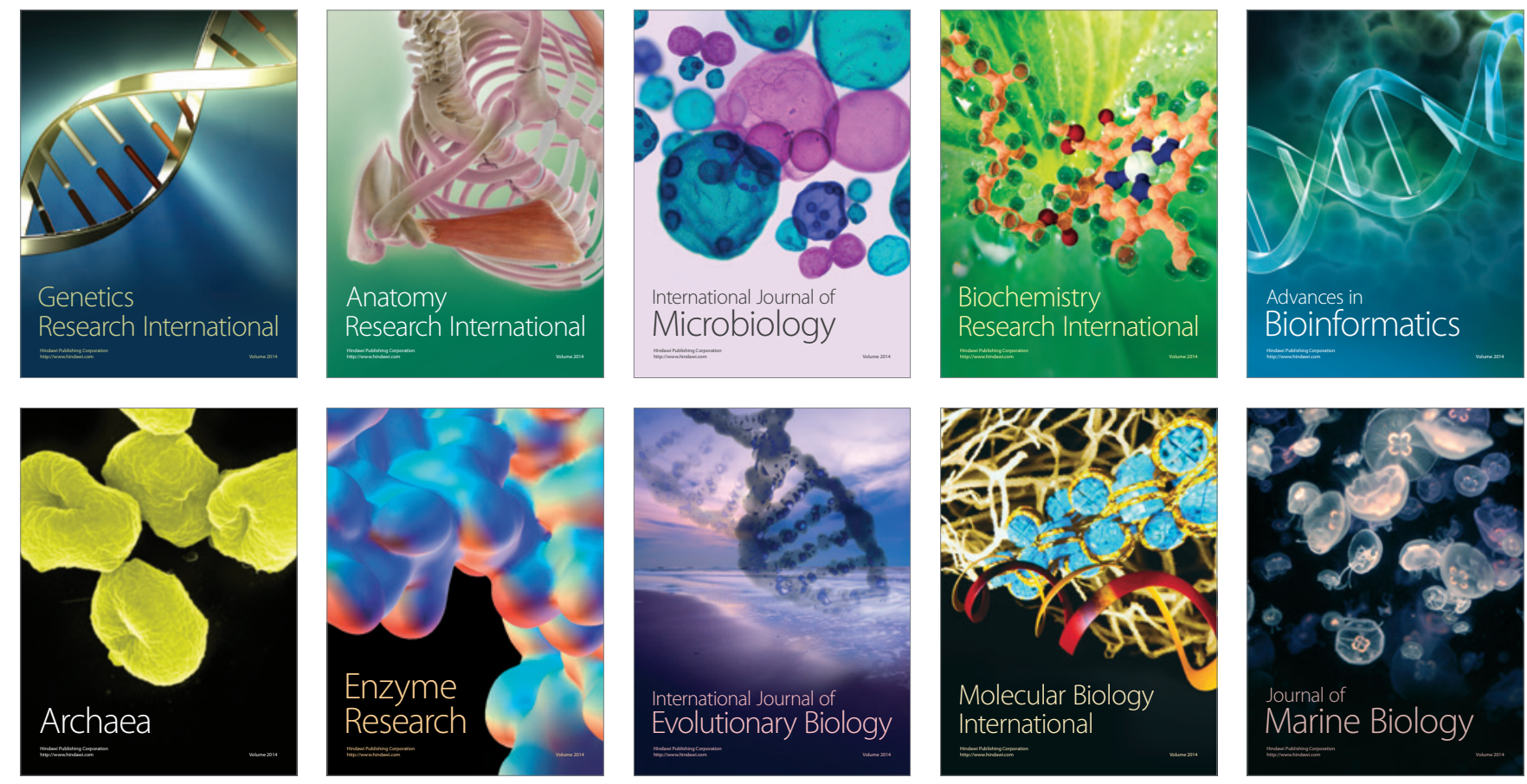